\title{
EN LA BÚSQUEDA DE LA ADAPTACIÓN Y LA RESISTENCIA: INNOVACIONES BIOLÓGICAS EN EL CULTIVO DE TRIGO EN MÉXICO, 1909-1941
}

\author{
Eva Rivas Sada \\ Tecnológico de Monterrey, campus Monterrey
}

\section{ALGUNAS CONSIDERACIONES SOBRE \\ LAS INNOVACIONES BIOLÓGICAS}

1 estudio sobre las innovaciones biológicas y su impacto en
el desarrollo agrícola es una línea de investigación relativamente nueva y de resultados prometedores. En parte se debe a la misma naturaleza del objeto de estudio, pues la investigación sobre las innovaciones biológicas en el agro suele realizarse desde tres amplios campos historiográficos: la historia de la ciencia, la historia económica y la historia ambiental. Ello contribuye a enriquecer las perspectivas de abordaje al ofrecer una imagen mucho más compleja de los fenómenos naturales implicados en la producción agropecuaria, más aún cuando se hace el esfuerzo de entrecruzar los tres campos.

Desde la historia económica, algunos especialistas consideran que la poca atención que se le ha prestado a los fenómenos agrobiológicos previos a la segunda posguerra se debe al impacto de ciertas hipótesis que demostraban que las innovaciones

Fecha de recepción: 28 de marzo de 2019

Fecha de aceptación: 10 de septiembre de 2019 
mecánico-ingenieriles habían sido el principal factor causante de los incrementos registrados en materia de productividad, en particular en la portentosa agricultura estadounidense. Y se han dedicado en los últimos años a refutarla con ciertos resultados muy sugerentes. De una forma semejante, se detectan las mismas tendencias en la historiografía económica mexicana para dicho periodo: se concentra en las innovaciones ingenieriles y el desarrollo de la agricultura de riego. ${ }^{1}$ Sobre las innovaciones biológicas, ésta se ha centrado en el "paquete tecnológico" de la revolución verde, desarrollado entre la Secretaría de Agricultura y la Fundación Rockefeller entre los años de 1943 y 1965, así como en el impacto de su comercialización a escala internacional. Existe una abundante literatura sobre esta línea de investigación y sus aportaciones críticas han sido de gran valor. ${ }^{2}$

Ahora bien, para estudiar las innovaciones biológicas en el agro de la primera mitad del siglo xx se requieren las siguientes consideraciones respecto al desarrollo tecnocientífico. La primera se refiere a la dificultad de analizar el conjunto de innovaciones biológicas -semillas híbridas, fertilizantes y plaguicidas-como un "paquete tecnológico", tal como se le estudia en el segundo periodo de posguerra. Los estudios históricos de las ciencias han mostrado que el desarrollo de cada una de las innovaciones biológicas fue hasta cierto punto autónomo y, en su conjunto, disímil en su temporalidad, al menos durante

${ }^{1}$ Para el primer caso, se recomienda Olmstead y Rhode, Creating Abundance, y "Biological innovation"; y Pujol-Andreu, "Wheat varieties". El debate referido gira en torno a la obra seminal de HaYAmi y RutTAN, Agricultural Development. Sobre la historiografía mexicana se ha prestado mucha atención a las grandes obras de ingeniería hidráulica construidas sobre los principales ríos del país. Consúltese uno de los clásicos, АвогтEs, El agua de la nación, y la abundante producción de la Asociación de Historia Económica del Norte de México.

${ }^{2}$ Entre los artículos, tesis doctorales y libros de este tema, posiblemente las obras más reconocidas por su criticismo a la revolución verde sean la de HewitT, La modernización, y la de CoTTER, "Before de the Green revolution". 
este periodo. ${ }^{3}$ Asimismo, hay que tomar en cuenta que en el campo de la ingeniería agronómica se desarrollaron modelos experimentales con fines distintos a los estrictamente científicos, orientados principalmente a incrementar la productividad. Consideramos que estas variantes experimentales fueron clave para el desarrollo tecnológico agrícola del periodo o, dicho de otro modo, fungieron como la base de las innovaciones biológicas, como se muestra en este trabajo. Para los fines de esta investigación destacan tres de ellos. Uno de los modelos experimentales más relevantes fue aquel que evaluaba la eficacia de ciertos insumos o productos en materia de productividad, por ejemplo, las pruebas de aclimatación de nuevas variedades o sobre la cantidad correcta de fertilizantes. Otro de los modelos fue el que puso a prueba, empíricamente, la eficiencia de ciertos procesos o técnicas agrícolas, tales como los ensayos de germinación de las semillas, o sobre la distancia óptima entre los surcos y la profundidad de la siembra. Por último, aquel modelo experimental con fines de demostración, es decir, para persuadir a los agricultores sobre la importancia de modificar ciertas prácticas culturales que han sido validadas formalmente. ${ }^{4}$

Lo anterior nos lleva, necesariamente, a reconocer lo estratégica y relevante que fue la colaboración con las asociaciones de productores y el trabajo individual de los agricultores en las experimentaciones para mejorar la productividad de sus tierras y cultivos. No obstante, consideramos que la experimentación

\footnotetext{
3 Todo parece indicar que el origen del paquete tecnológico de la posguerra hunde sus raíces en la segunda mitad del siglo xIx. Por ejemplo, si se traza el origen de los fertilizantes éste daría inicio en 1840, con los estudios sobre química orgánica. Las semillas mejoradas datarían de la última década del siglo antepasado, cuando inició la recuperación de las teorías mendelianas. Los plaguicidas a partir de 1913, cuando se logró la síntesis química. BERnaL, La ciencia en la historia, pp. 603-609, 627-631; Allen, La ciencia de la vida, pp. 108-164; Derry y Williams, Historia de la tecnología, pp. 994-1002.

${ }^{4}$ HaRwood, "Comments en experimentation", pp. 326-328.
} 
informal realizada por los agricultores, de prueba y error, ${ }^{5}$ fue y seguirá siendo la piedra angular del desarrollo de la agricultura, si se le entiende a ésta en su aspecto más básico, como la práctica civilizatoria centrada en la domesticación y explotación de especies y variedades, y su constante acondicionamiento a las particularidades del entorno. Estas consideraciones nos ayudan a comprender cómo es que se registraron ciertos avances en materia de productividad, e incluso el desarrollo de nuevos cultivos, al margen de las instituciones científicas o ante su limitada capacidad de acción. Al menos eso es lo que nos muestra la información empírica para el caso mexicano.

Uno de los problemas más comunes cuando se estudia el fenómeno de las innovaciones biológicas es la invisibilidad de estos cambios técnicos resultantes de la experimentación empírica, los cuales quedan ocultos en las prácticas de cultivo; de ahí la gran dificultad para medir su impacto. Esto cobra mayor relevancia en el caso específico del mejoramiento genético de las semillas y su creciente utilización. Como bien lo expresa Dalrymple: "This relative silence is partly due to the unobstrusive nature of the higher-yielding varieties. They did not look much different from their predecessors". ${ }^{6}$ De ahí la necesidad de prestar atención, en este trabajo, a la taxonomía de las variedades de trigo y relacionarlas con sus nombres comunes (trigos duros rojos invernales, blancos sin barbas, suaves y de primavera, semoleros de invierno, etcétera).

También existe otra dificultad, consistente en el relativo corto tiempo de utilización de las semillas mejoradas a causa del

\footnotetext{
5 Uno de los errores frecuentes al momento de estudiar el periodo se debe a la idea generalizada de atribuirle al quehacer científico los avances más relevantes en materia agronómica. Tal como lo expresa Harwood: "This is the informal exploration of products and processes which, arguably, most farmers themselves have always conducted: what might be called 'cut and try"'. HARwOOD, "Comments of experimentation", p. 327.

6 Dalrymple, "Changes in wheat varieties", p. 22.
} 
"efecto de la reina roja". ' Esta noción es una de las más importantes contribuciones de la historia ambiental a la comprensión de los fenómenos agrobiológicos. ${ }^{8}$ Las constantes alteraciones que la actividad agrícola ha generado en los entornos medioambientales, principalmente en las grandes zonas de monocultivo desarrolladas en el último siglo, han provocado la evolución de insectos y otros agentes patógenos de forma continua, de ahí la necesidad permanente de los agricultores de introducir variedades nuevas o perfeccionadas. En el caso específico del mejoramiento del trigo en México, se pretendía superar la alta vulnerabilidad de los trigos criollos al ataque del chahuistle (o roya), una enfermedad fungosa con gran capacidad de mutación, como trataremos de mostrar en este trabajo.

\section{LAS INNOVACIONES BIOLÓGICAS EN PERSPECTIVA HISTÓRICA}

Las innovaciones biológicas pueden definirse como aquellos conocimientos, productos y técnicas que han permitido aumentar el grado de control y manipulación del potencial genético y del ciclo de desarrollo biológico de los organismos en explotación, en aras de la productividad, de la calidad, e incluso de la propia viabilidad de la actividad productiva. Estas se agrupan en tres amplios campos de acción: el mejoramiento genético de los cultivos, el uso eficiente de los recursos elementales de los que depende el buen desarrollo de los cultivos y la prevención de enfermedades y ataque de plagas. En esta ocasión, nos centraremos

\footnotetext{
7 Se le conoce como "efecto de la reina roja" en alusión al personaje literario de Alicia a través del espejo, de Lewis Carroll. El mandato de la reina roja a sus súbditos consistía en correr, sin freno, para quedar siempre en el mismo lugar. En términos biológicos, se refiere a la adaptación continua de las especies para mantenerse en el mismo entorno.

8 Por ejemplo, los trabajos de Russell, "Evolutionary History" y Russell, Allison, Finger, Brown, Balogh y Carlson, "The Nature of Power".
} 
en el desarrollo y mejoramiento de las semillas para elevar la productividad de las cosechas y, parcialmente, en su relación con el combate de plagas y enfermedades, en la etapa previa al desarrollo de los híbridos artificiales de laboratorio.

Consideramos que la agricultura comercial entró en una segunda etapa de transformación productiva cuando los conocimientos y técnicas tradicionales de cultivo fueron superados a la luz de ciertas teorías científicas postuladas y perfeccionadas dentro del complejo campo de los estudios biológicos. Su traducción tecnológica fue posible, entre otros factores, por la emergencia de la ingeniería agronómica a partir del último tercio del siglo xIX y su gran desarrollo en el siguiente siglo. ${ }^{9}$ La racionalidad científica que marcó las diversas trayectorias tecnológicas sobre los fenómenos agrobiológicos tuvo como propósito hacer de la agricultura un sistema de alta productividad y de calidad estandarizada que respondiera a la creciente demanda de la agroindustria moderna y a los gustos y tendencias del consumo urbano. ${ }^{10}$ De ahí que las innovaciones biológicas se manifestaran con mayor intensidad en aquellas zonas dedicadas a la agricultura comercial.

Sin entrar en detalle en la historia de las ciencias consideremos que, durante la segunda mitad del siglo xIx y los primeros años del xx, la comunidad científica había logrado identificar los factores biológicos clave de la productividad de las cosechas. Se descubrieron, primero, los recursos elementales que incidían directamente en el crecimiento óptimo de los cultivos:

\footnotetext{
${ }^{9}$ Durante el siglo xIx, las disciplinas que más aportaron a la configuración de la ingeniería agronómica fueron la química, la física y la historia natural; y estas, a su vez, fueron sostenidas por el desarrollo instrumental -intelectual y material- para la experimentación: los avances matemáticos, el método científico, junto con los instrumentos de laboratorio y de campo.

${ }^{10}$ Sobre el modelo baconiano de la revolución científica y su estrecha relación con la revolución industrial consúltese ELENA y ORDóÑEZ, “De la revolución científica”.
} 
la irradiación, el agua y los nutrientes de los suelos (nitrógeno, fósforo y potasio).$^{11}$ Se creyó que el uso eficiente de los mismos llevaría a un crecimiento sostenido de la productividad, incluso en zonas agroecológicas poco favorables o en periodos naturales adversos (sequías, por ejemplo). A inicios del siglo pasado se identificó a la especificidad fisiológica de las variedades en explotación como el otro factor clave de la productividad, la cual estaba directamente relacionada con el aprovechamiento óptimo de dichos recursos y con la capacidad de resistencia a las enfermedades y al ataque de agentes patógenos. Este conjunto de descubrimientos abrió nuevos campos de investigación y de desarrollo tecnológico: por un lado, los estudios sobre las relaciones planta-suelo y planta-clima (la fenología), que llevaron, por ejemplo, al desarrollo de fertilizantes; por el otro, los estudios sobre los mecanismos que rigen la transmisión de la herencia, con el propósito de mejorar el potencial genético de las variedades en explotación. ${ }^{12}$

Para los casos de México, Estados Unidos y Canadá se han identificado tres etapas consecutivas en el mejoramiento genético del trigo para el periodo histórico analizado: a) introducción de variedades exóticas de mayores rendimientos; $b$ ) selección y aislamiento de líneas puras provenientes de las variedades exóticas; c) creación de nuevas variedades por cruzamiento (hibridación), seguido de selección y aislamiento de las nuevas líneas obtenidas. ${ }^{13}$

\footnotetext{
11 En referencia a los estudios pioneros de Von Liebig en 1840, considerado el padre de la química orgánica, BERNAL, "La ciencia en la historia”, pp. 603-604. 12 Cara García, "Notas para la historia”, p. 16; Reynolds, Pask, Mullan y Chávez-Dulanto, Trigo. Fitomejoramiento, prólogo. Un buen ejemplo en el siglo xix fueron los fertilizantes naturales, tales como el guano de Perú y los nitratos de Chile.

13 Dalrymple, "Changes in wheat varieties", p. 23. Una de las dificultades más significativas en el desarrollo de los híbridos consiste en que las flores son completas y suelen autofecundarse, lo que hace que se pierda el vigor híbrido de las nuevas líneas.
} 
El procedimiento preponderante para la obtención de variedades mejoradas hasta el siglo XIX consistió en la capacidad de observación del agricultor para seleccionar los mejores ejemplares de la cosecha y luego reproducirlos en el siguiente ciclo. Las nuevas variedades se obtenían espontáneamente, por hibridación natural, entre las plantas nativas y las exóticas. ${ }^{14} \mathrm{En}$ los albores del siglo xx, los agrónomos, en colaboración con los agricultores, se lanzaron a la tarea de buscar el fenotipo extremo, es decir, a desarrollar aquellas variedades que, por hibridación asistida, mostraran el mayor rendimiento de los recursos (irradiación, agua y nutrientes) y en cualquier tipo de medioambiente. Tuvo su fundamentación teórica en la genética cuantitativa de las poblaciones y en el control y análisis estadísticos de los experimentos de campo para el control de cruzas. ${ }^{15}$ Pudiera considerarse como la antesala de lo que hoy conocemos como ingeniería genética y de los transgénicos; la transformación de la fitotecnia en fitogenética. ${ }^{16}$

\section{EL SURGIMIENTO DE LOS TRIGOS MODERNOS}

Una de las consecuencias de lo anterior fue la creciente reducción de las especies de trigo en explotación dentro de la

14 Olmstead y Rhode, Creating abundance, pp. 17-63.

15 Reynolds, Pask, Mullan y Chávez, Trigo. Fitomejoramiento, prólogo. CAÑón, en Manual del curso define a la genética cuantitativa como "la ciencia que tiene como objeto de estudio los caracteres cuantitativos”. Según el curso, sobre genética cuantitativa de la Universidad de Barcelona, "cualquier carácter fenotípico (morfológico, fisiológico, conductual) que toma distintos valores cuantificables en diferentes individuos y no sigue un patrón de herencia mendeliana simple es un carácter cuantitativo. Para describir su variación se utilizan métodos estadísticos tales como la media y la varianza”. "Génetica cuantitativa”, Curso en línea. Universidad de Barcelona, en bioinformatica.uab.es/.../ documents/5Cgenetica_gen/5CTema/209/20Herencia/2.

16 Sobre este último desarrollo, consúltese Allen, La ciencia de la vida, pp. 272-307. 
agricultura comercial. Según los especialistas en la gramínea, las variedades desarrolladas pertenecen a solo dos especies: Triticum aestivum y Triticum durum. ${ }^{17}$ Sus nombres comunes se conjugaban, sencillamente, en trigos paneros (T. aestivum) y trigos semoleros o cristalinos (T. durum). A los trigos paneros se les distinguía además como suaves y duros según la proporción de gluten; los de mayor contenido eran los trigos de los que se obtenía la sémola, los más duros de todos. En el campo, se hacían además otras distinciones como la coloración de la espiga-blancos o rojos, o colorados en México- o por tener o no argaña (o barbas en México). Claro está que la creciente preferencia industrial por las variedades de las especies aestivum y durum se debía a la obtención de harinas de mejor calidad, pero también a que sus granos eran más fáciles de $\operatorname{moler}^{18} \mathrm{y}$ a la creciente especialización de los mercados de consumo. Por ejemplo, para la elaboración industrial de harinas multipropósito se demandaban tanto trigos suaves como duros para su mezcla; las harinas elaboradas con trigo suave se destinaban exclusivamente a la repostería; las harinas de semolero o cristalino se utilizaban para la elaboración de pastas alimenticias. ${ }^{19}$

Al respecto, no hay que olvidar que las características fisiológicas de las especies y variedades en explotación fueron producto de un largo proceso evolutivo de adaptación a las condiciones

17 Desde la perspectiva de la genética, el Triticum durum es una especie tetraploide, el Triticum aestioum, hexaploide, y las especies de trigo ancestrales son diploides. Actualmente, se reconocen 21 especies y 2 subespecies, la mayoría domesticadas con fines alimenticios. ITIs (Integrated Taxonomic Information System), "Wheat" en itis.gov. Consultado el 23 de noviembre de 2018.

${ }_{18}$ A fines del siglo XIX, uno de los grandes especialistas en trigo consideraba que los trigos ancestrales, como el Triticum spelta y el Triticum einkorn, estaban destinados a desaparecer, pues la cáscara de las semillas era sumamente dura de molerse y por ello los molineros las desdeñaban. Vilmorin, Los trigos. 19 Peña, Ortiz-Monasterio y Sayre, "Estrategias para mejorar", p. 292. Actualmente, las harinas de trigo se utilizan además como aditivos para un sinnúmero de alimentos procesados. 
ecológicas de cada zona triguera. De este milenario y complejo proceso surgió una de las características agronómicas más significativas del cultivo: el hábito de vernalización. ${ }^{20}$ Los trigos suaves fueron adaptados a las zonas templadas-frías, de mayor humedad y suelos más fértiles, de ahí que se desarrollaran en la Europa central y nórdica. Se les conocía comúnmente como trigos de invierno, ya que sus variedades requieren, para entrar en floración, de largos periodos de exposición a temperaturas muy bajas (menores a 6 grados y expuestos de 30 hasta 60 días), razón por la cual se siembran en otoño. Los trigos duros y los semoleros fueron adaptados a las regiones más áridas, en las que predominan el estrés hídrico y los suelos más pobres; particularmente en el Medio Oriente y en la gran región agrícola que integra el Mediterráneo. Fueron conocidos como trigos de primavera al no poseer dicho hábito, es decir, por requerir temperaturas relativamente más altas y un tiempo de exposición menor al frío para entrar en floración, de ahí que su siembra fuese a inicios de la primavera. Por lo anterior, el hábito de vernalización y su íntima relación con el calendario agrícola y con las especificidades climáticas de las zonas agrícolas constituyeron un fuerte condicionante en el mejoramiento genético del cultivo.

En el caso particular de Canadá y Estados Unidos, el desarrollo de trigos híbridos durante el siglo XIX se convirtió en una tarea ineludible en el proceso de colonización territorial del oeste, cuya heterogeneidad agroclimática obligó, tanto a migrantes como a colonos, a experimentar con cientos de nuevas semillas

${ }^{20}$ La domesticación del trigo silvestre data de hace 12000 años y se ubica en las primeras civilizaciones del antiguo Próximo Oriente, región que se convirtió en el principal centro de dispersión de la cultura triguera al resto del mundo, ITIs (Integrated Taxonomic Information System). "Wheat" en itis. gov. Consultado el 23 de noviembre de 2018. Cabe mencionar que fue hasta 1928 cuando las investigaciones científicas llevadas a cabo por Nikolai Vavilov, considerado el padre de la genética en Rusia, explicaron el hábito de la vernalización de los trigos. Crow y Dove, "N. I. Vavilov, Marthyr”. 
importadas, tanto de trigos primaverales como de invierno. ${ }^{21} \mathrm{En}$ este contexto, la fundación del Departamento de Agricultura (USDA) en 1862, y poco después de los Colegios y Estaciones Experimentales estatales, fueron el parteaguas del mejoramiento de los cultivos en Estados Unidos. ${ }^{22}$ Se logró desarrollar un conjunto de híbridos de gran productividad, lo que permitió, primero, la expansión de la frontera agrícola triguera (véase el mapa 1) y, ya en el último tercio del siglo xIx, la consolidación del cultivo como actividad comercial. Destacan los híbridos Red Fire, White Fife, Marquis y Turkey, estos últimos de gran impacto en el agro mexicano. ${ }^{23}$

Algo semejante sucedió en Europa. De acuerdo con PujolAndreu, desde inicios del siglo xIx, el gobierno francés fue pionero en la promoción del fitomejoramiento del cultivo. Agricultores y botánicos desarrollaron una gran cantidad de híbridos. Destaca en la época la labor de la compañía de semillas de V. L. de Vilmorin, la cual desarrolló híbridos primaverales de trigo panero, especialmente los suaves, para mejorar la calidad de las harinas, tales como el Bordier, Trésor, Bon Fermier, entre otros. ${ }^{24}$ También desarrolló el trigo Noé o de Aquitania, trigo duro, especial para las tierras más áridas del sur mediterráneo. Se suman a la tarea las empresas semilleras italianas de F. Todaro y de N. Strampelli, con los muy populares trigos duros

${ }^{21}$ Sobre la experimentación y desarrollo de híbridos de trigo en el oeste de Estados Unidos, consúltese Serrano y Rivas, "Teoría y práctica”.

${ }^{22}$ TRue, A History of Agricultural Experimentation, pp. 41-61.

23 Olmstead y Rhode, Creating Abundance, pp. 25-40. Dalrymple estima que entre 1919 y 1954, la Turkey fue la variedad más importante de todas, con una superficie total cultivada para ese periodo de 93517500 acres; le seguiría la Marquis, con 47598500 acres para el mismo periodo referido. DalRYMPLE, "Changes in wheat varieties", p. 25.

${ }^{24}$ Pujol-Andreu, "Wheat varieties", pp. 78-83. Vilmorin publicó uno de los catálogos más completos de trigos mejorados que existían en Europa a finales del siglo Xix. Consúltese Vilmorin, Los trigos. 


\section{Mapa 1 \\ EXPANSIÓN DE LA AGRICULTURA TRIGUERA \\ EN ESTADOS UNIDOS, 1839-1909}

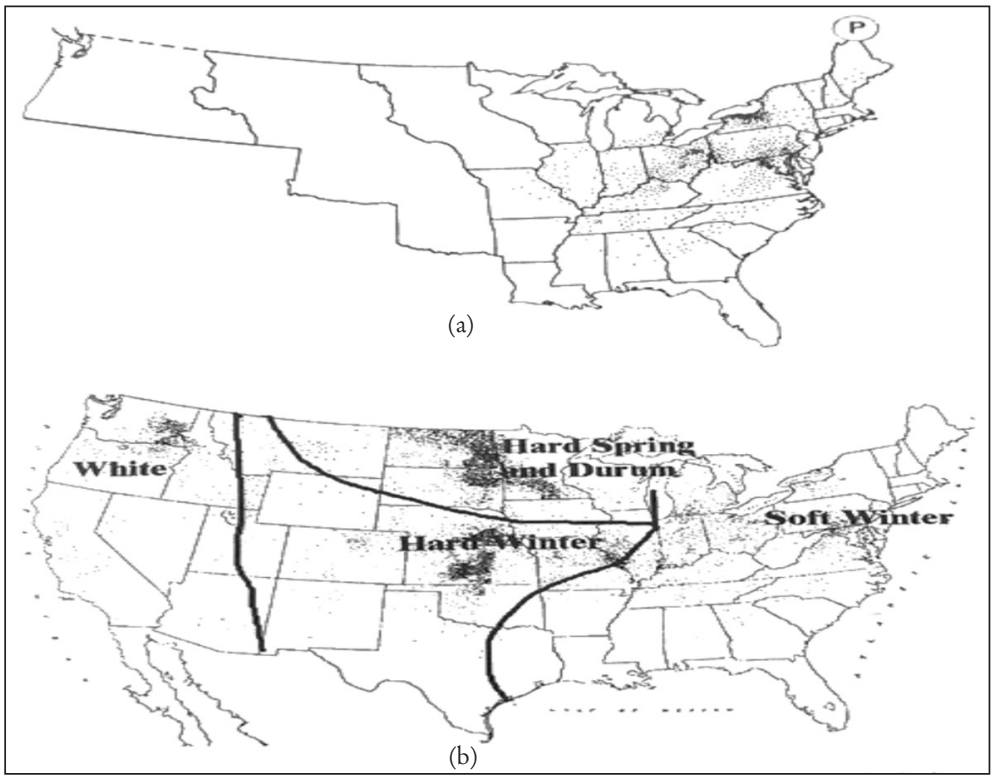

Fuente: Olmstead y Rhode, Creating Abundance, p. 23.

Nota: en el mapa a) cada punto representa 100000 bushels de trigo, en el $b$ ) 50000 bushels.

White: trigos blancos, suaves; Hard Spring: trigos duros de primavera; Durum: trigos duros o semoleros; Soft Winter: trigos suaves de invierno.

y semoleros Mentana, Villa Glori, Damiano Chiesa y Senatori Capelli. ${ }^{25}$ Algunos de los trigos desarrollados por dichas empresas fueron introducidos en México, como se verá líneas adelante.

Lo importante a destacar es que la creciente distribución internacional de semillas a partir del último cuarto del siglo XIX marcó una clara tendencia de sustitución de trigos locales autóctonos

${ }^{25}$ Esfuerzos semejantes se realizaron en Alemania, Países Bajos, Suecia y Gran Bretaña, según el mismo autor. 
por aquellos híbridos y mejorados de mayor productividad, una práctica que mostraba ya solidez en las primeras décadas del siglo xx. Como resultado de lo anterior, entre 1866 y 1930, la agricultura estadounidense registró un incremento de $23.8 \%$ en los rendimientos del trigo, al pasar de 859.9 a $941.5 \mathrm{~kg}$ por ha. ${ }^{26}$ Algo semejante se registra en aquellos países europeos con las tierras más fértiles y propicias para el cultivo del trigo, en donde rondaron la t por ha, con un incremento medio de $15 \%$ (véase la tabla 1). Nótese que, en aquellos con condiciones más áridas y adversas al cultivo, el incremento porcentual fue mayor, si bien en términos absolutos el volumen de las cosechas giró en torno a la media tonelada por hectárea.

\section{Tabla 1}

INCREMENTOS EN LOS RENDIMIENTOS DEL TRIGO, 1870-1939

\begin{tabular}{lccllccc}
\hline & \multicolumn{2}{c}{$1870-1915$} & & \multicolumn{2}{c}{$1916-1939$} & \\
\cline { 2 - 3 } \cline { 6 - 7 } & $q / h a$ & $k g / h a$ & & $q / h a$ & $k g / h a$ & Incremento \% \\
\hline Gran Bretaña & 19 & $861.6-965.2$ & & 22 & $997.7-1117.6$ & 15.7 \\
Francia & 13.5 & $612.2-685.8$ & & 15.5 & $702.9-787.4$ & 14.8 \\
Italia & 8.5 & $385.4-431.8$ & & 14 & $634.9-711.2$ & 64.7 \\
España & 7 & $317.4-355.6$ & & 9 & $408.1-457.2$ & 28.5 \\
\hline
\end{tabular}

FUENTE: elaboración propia con base en cifras de PUJOL-ANDREU, "Wheat varieties". Nota: para la conversión de quintales a kilogramos se utilizaron las dos equivalencias de quintal prevalecientes en el periodo, el quintal "corto" estadounidense con un valor de $45.35 \mathrm{~kg}$, y el quintal “largo" británico, con una equivalencia de $50.8 \mathrm{~kg}$, razón por la cual se estableció como rango.

Si bien es cierto que en el caso de México existía el cultivo en casi todas las entidades del país con una superficie media para el periodo de alrededor de $500000 \mathrm{ha},{ }^{27}$ a inicios del siglo pasado

${ }^{26}$ De 11.3 a 14 bushels por acre, según Olmstead y Rhode, Creating Abundance, p. 59. Para la conversión: un bushel/acre es igual a $67.25 \mathrm{~kg} / \mathrm{ha}$.

27 Por ejemplo, para 1900, del total de la superficie cultivada con granos a nivel nacional, el maíz representaba $74.4 \%$ con algo más de 4000000 de ha 
destacaban dos regiones trigueras de larga data en las que recaía el cultivo comercial: las tierras del Bajío y las del altiplano central mexicano. Se le sumaban ciertas zonas dispersas a lo largo de las grandes sierras Madre Occidental y Oriental (véase el mapa 2). Dado el clima templado, predominaban los trigos paneros suaves. ${ }^{28}$ Conocidos como trigos criollos, las variedades mexicanas del T. Aestivum se introdujeron tempranamente en los inicios del periodo colonial, primero en los valles de México, Puebla y Tlaxcala, en donde se cultivaba junto con el maíz y el frijol, luego en las tierras aledañas a los fundos mineros que se fueron abriendo en la medida que se exploraba y colonizaba el territorio novohispano. ${ }^{29}$ Con los siglos se obtuvieron variedades mejor adaptadas a las diversas condiciones agroecológicas del país, si bien todas poseían una mayor resistencia al estrés hídrico. Por tal motivo, los ingenieros agrónomos del periodo los consideraban como trigos nativos o naturalizados. ${ }^{30}$

El trigo era un cultivo invernal por excelencia, cuyo ciclo iniciaba en el otoño. Empero, no deja de llamar la atención que los trigos criollos fueran variedades sin el hábito de vernalización, las cuales, en otras latitudes como la europea y Estados Unidos, se habían desarrollado durante el periodo primaveral. Tal práctica cultural obedecía al hecho de que los inviernos en México eran mucho más benignos y las variedades primaverales no sufrían los estragos de las bajas temperaturas. Pero el hecho más relevante de que se cultivaran variedades primaverales en la temporada otoño-invierno obedecía a la prevención de las

cultivadas, le seguía en orden de importancia el frijol con $12.1 \%$ y 1000000 de ha, $\mathrm{y}$ en tercer lugar el trigo con $11.6 \%$, con 500000 ha en números redondos. México en el siglo XX, p. 54.

${ }^{28}$ En algunas zonas de montaña del altiplano central y en las grandes sierras Madre Occidental y Oriental se cultivaban algunas pequeñas superficies con trigos duros, pero en realidad su producción escaseaba.

29 Rodríguez, Producción y consumo, p. 20.

$30 \mathrm{RFA}$, fondo 126 6.13, Informe de la experimentación con trigos, Secretaría de Agricultura y Fomento, 1943, serie 1.1, c. 32, exp. 355, sf. (1943). 


\section{Mapa 2}

PRINCIPALES ZONAS TRIGUERAS Y PRODUCCIÓN ESTIMADA, 1879

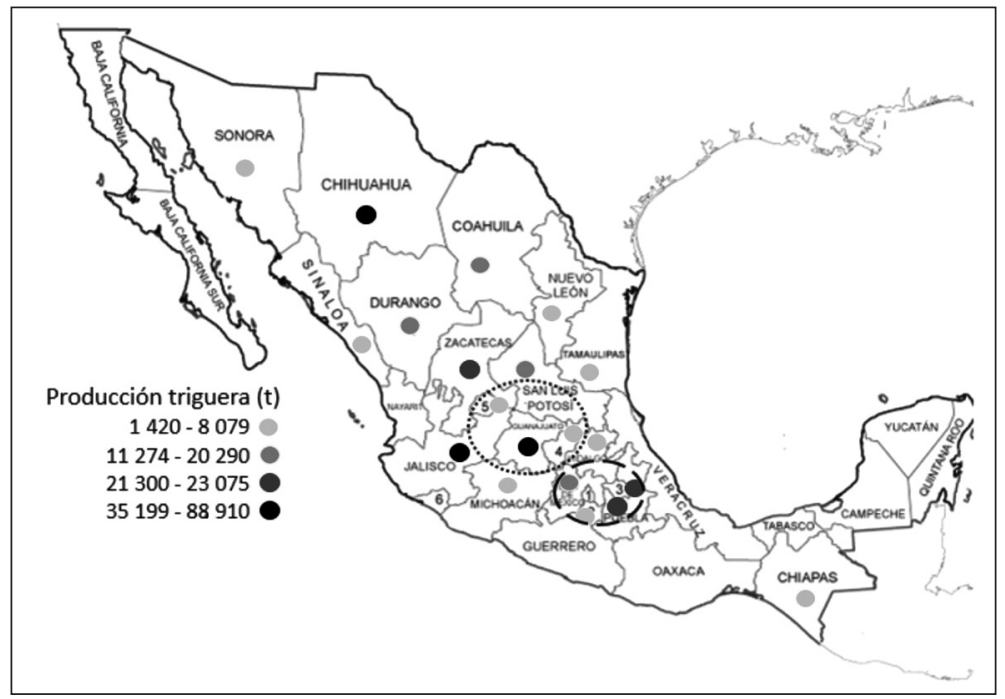

Fuente: modificado del original, Florescano, Atlas histórico, p. 139.

enfermedades fungosas, particularmente al ataque del chahuistle. ${ }^{31}$ El calendario del ciclo agrícola se había definido para evitar la temporada de lluvias de la primavera, cuya humedad creaba las condiciones idóneas para la reproducción de las enfermedades. Pese a que los trigos criollos ya poseían cierta capacidad de resistencia a la sequía, la baja humedad típica del periodo invernal en México causaba un estrés hídrico importante, lo que afectaba negativamente a la productividad del cultivo, así como a la calidad de las harinas obtenidas. Sin embargo, para los agricultores era preferible realizar la siembra en el otoño, aun cuando la cosecha fuese menos rendidora, que arriesgarse

${ }^{31}$ Su nombre científico es Puccinia graminis. Es un hongo microscópico que ataca las gramíneas ennegreciéndolas. 
al ciclo primaveral, en el que podía perderse toda la cosecha debido al chahuistle o al ataque del tizón o el carbón. No obstante, con frecuencia se suscitaban epifitias severas que arrasaban los campos de sembradío.

El impacto productivo de las innovaciones biológicas que se habían desarrollado previo al siglo xx no fue menor. Las variedades criollas de trigo panero suave adaptadas al estrés hídrico de la temporada invernal para evitar así el chahuistle ofrecieron buenos rendimientos a los agricultores mexicanos, como puede observase en la tabla 2. Tal combinación permitió la obtención de algo más de media tonelada de trigo por ha, un volumen que se acercaba a lo obtenido en Francia, cuyas tierras eran naturalmente óptimas para el cultivo, y evidentemente mucho más alto que las regiones agrícolas del Mediterráneo europeo, con las que se compartía condiciones agroclimáticas semejantes, en donde se obtenía un tercio de tonelada por hectárea.

\section{Tabla 2}

COMPARATIVO DE RENDIMIENTOS MEDIOS

ENTRE PAÍSES, 1870-1917

\begin{tabular}{lll}
\hline Periodo & País & Rendimientos $(\mathrm{kg} / \mathrm{ha})$ \\
\hline $1897-1912$ & México & 570 \\
$1870-1915$ & Francia & $612.2-685.8$ \\
$1870-1916$ & Italia & $385.4-431.8$ \\
$1870-1917$ & España & $317-4-355.6$ \\
\hline
\end{tabular}

FuENTE: para la estimación de los rendimientos en México, Estadísticas históricas; para los países europeos, PUjol-Andreu, "Wheat varieties".

Mas los nuevos híbridos desarrollados en los últimos años del siglo xIx en América del Norte y en algunos países europeos generaron grandes expectativas entre autoridades, ingenieros agrónomos y agricultores en México. La constitución del aparato estatal para el fomento del mejoramiento genético del cultivo 
se dio hasta los inicios del siguiente siglo, cuando el gobierno federal lanzó programas más ambiciosos para la modernización del campo.

\section{EL INICIO DE LOS PROGRAMAS DE FITOMEJORAMIENTO Y LAS SEMILAS EXÓTICAS}

La investigación realizada hasta el momento nos permite reconocer el origen de los programas e instituciones estatales en materia de fitomejoramiento en el periodo porfiriano tardío y primeros años de la revuelta revolucionaria (1909-1916). Pero, ¿̇por qué hasta ese entonces? Según Zuleta, había otras prioridades más urgentes de atender, como los problemas monetarios, fiscales, de comunicación y comerciales, que habían hecho postergar las iniciativas estatales en materia de fomento agrícola. ${ }^{32}$ Mas la misma autora deja claro que el tema se retomaba cuando se suscitaban crisis agrícolas y la opinión pública así lo reclamaba. Según el mismo secretario de Fomento, Olegario Molina:

El criterio público, bien orientado comúnmente, no carece de razón al expresar este deseo, pues en un país nuevo como el nuestro, donde la iniciativa privada no alcanza todavía un alto grado de desarrollo y donde son tradicionales las deficiencias de la explotación agraria, la acción del gobierno estimulando y creando fuerzas nuevas que vengan a obrar sobre fuentes de productos inexplotados, será de utilidad indiscutible [...].

En ese sentido, se suscitaron algunas coyunturas que obligaron al gobierno federal a tomar medidas de urgencia: una crisis generada por una serie de plagas incontrolables que estaban afectando las principales zonas de monocultivo comercial tanto

32 Zuleta, "La Secretaría de Fomento", pp. 11-12. 
en Estados Unidos como en México en los primeros años del siglo pasado, ${ }^{33} \mathrm{y}$ agravada por una crisis alimentaria provocada por las sequías entre 1907 y 1908. Quizá también se deba a que en el contexto internacional había claras señales de la importancia creciente que estaba adquiriendo la agricultura comercial en el mercado internacional de productos agrícolas, que en buena medida encabezaba Estados Unidos.

En este contexto, Olegario Molina lanzó una serie de iniciativas de ley entre 1907 y 1910 que reformaban el aparato institucional de la Secretaría de Fomento para promover la agricultura nacional. Específicamente, en 1909, se creó la ley que dio origen a la organización de un sistema nacional de investigación y extensión agrícolas. Según Cervantes y Saldaña, el secretario se basó en el modelo francés constituido por "escuela-estación agrícola-revista de divulgación-sindicato agrícola”.$^{34}$ La reforma contempló, entre otros cambios, la creación de la Estación Agrícola Central bajo el control de la Escuela Nacional de Agricultura, de estaciones experimentales regionales, ${ }^{35}$ y la fundación de sociedades estatales de agricultores, que organizaron a los principales productores de las diversas zonas agrícolas del país

${ }^{33}$ Nos referimos a las plagas del picudo algodonero, la langosta y la mosca de la fruta que afectaron a ambos países desde los primeros años del siglo pasado. Ello obligó a la Secretaría de Fomento a crear la Comisión Nacional de Parasitología, entidad responsable de la política fitosanitaria. Véase al respecto Itıé, “50 años", pp. 63-77.

34 Cenvantes y Saldaña, “Las estaciones experimentales”, p. 338.

35 Para 1915 se habían creado estaciones experimentales en las siguientes localidades: la Estación Central en los campos próximos a la ciudad de México, bajo jurisdicción de la Escuela Nacional de Agricultura; en Río Verde, San Luis Potosí; en Oaxaca, capital; en San Juan Baustista, Tabasco; y la de Ciudad Juárez, Chihuahua. Y los siguientes campos experimentales: en Juchitán, Oaxaca (dedicada a cultivos tropicales), en San Rafael, Jalisco; Ranchería, Chihuahua; Don Martín y La Fragua en Nuevo León, y otra más en Yucatán. BJLLO, Memoria de la Secretaría de Fomento presentada al Congreso de la Unión por el Secretario de Estado y del Despacho del Ramo, Lic. Olegario Molina (corresponde al ejercicio fiscal 1909-1910), anexos. 
para que éstos definieran los problemas productivos locales a atender y contribuyeran, además, a la financiación necesaria para ello. Con esta reforma, como bien ha señalado Zuleta

[...] no sólo se pretendía promover el perfeccionamiento de las técnicas y prácticas de cultivo de los productos potencialmente exportables, como se había intentado desde la década de 1880 , sino también el mejoramiento de los tradicionales, maíz, frijol, chile, trigo, papa, arroz, principalmente cultivados para el consumo interno, ignorado hasta entonces por las preocupaciones gubernamentales. Las esperanzas de regeneración se volcaron hacia adentro [...] sólo cuando se miró hacia adentro, se definió y puso en marcha el primer programa integrado y coherente para el fomento agrícola del país. ${ }^{36}$

Con la nueva organización e infraestructura experimental, el gobierno lanzó su primer esfuerzo de mejoramiento de los cultivos mediante la introducción de variedades exóticas para la obtención de híbridos naturales de mejores rendimientos, siguiendo el modelo exitoso de la USDA, ya probado desde el siglo XIX. ${ }^{37}$ Esta estratégica labor estuvo a cargo de la Estación Agrícola Central, la cual inició los trabajos experimentales para la evaluación de la productividad y la aclimatación de las nuevas variedades introducidas, así como realizó unos primeros esfuerzos para la obtención de híbridos y líneas puras. ${ }^{38}$

36 Zuleta, “La Secretaría de Fomento”, p. 18.

37 Posiblemente una de las introducciones de nuevos cultivos en Estados Unidos sea la del cultivo de naranjas, que produjo un gran auge económico en la agricultura de California en las primeras tres décadas del siglo xx. Rivas, "La constitución".

38 Entre las funciones de la Estación Agrícola Central, la ley establecía: “estudiar las variedades nuevas de plantas y semillas, para resolver cuáles convenga introducir al país; mejorar las plantas más generalmente cultivadas por los medios de selección e hibridación; hacer el reconocimiento de las semillas que los agricultores quieran someter a ensayo". BJLlo, Memoria de la Secretaría de Fomento presentada al Congreso de la Unión por el Secretario de Estado y 
La distribución de semillas importadas en las principales zonas de cultivo requería necesariamente de la creación de los servicios de propaganda, los cuales fueron instituidos en 1910,39 pero también exigía la implementación del modelo experimental con fines de demostración. Para ello, se tornó necesario formalizar la colaboración con los agricultores mediante "la celebración de contratos para siembras o plantaciones que a la vez que sirvan como campos de demostración, puedan utilizarse como almácigos o semilleros destinados a la propagación que se persiga [...]". ${ }^{40}$ La reformada Secretaría buscaba impulsar un cambio profundo en los agricultores mexicanos, pues esperaba que éstos se asumieran como fitomejoradores:

La distribución especial de semillas de distintas variedades de maíz y trigo [fue] iniciada con el propósito de fijar la atención de los agricultores sobre la conveniencia de elegir cuidadosamente las semillas que se acomoden a las condiciones locales o respondan a propósitos determinados y de ponerlos en aptitud de elegir la que más convenga a sus necesidades $[\ldots]{ }^{41}$

Pese a la inestabilidad política y la confrontación ideológica, los gobiernos en turno coincidieron en la orientación básica de los programas de mejoramiento del cultivo del trigo. La introducción de nuevas variedades de alto rendimiento tuvo

del Despacho del Ramo, Lic. Olegario Molina (corresponde al ejercicio fiscal 1909-1910), anexos, p. 266.

${ }^{39}$ Los servicios de propaganda tenían como parte de sus objetivos "propagar las plantas o semillas de más altos rendimientos e introducir nuevos cultivos de resultados más provechosos que los que se practican actualmente".

${ }^{40}$ BJLLO, Memoria de la Secretaría de Fomento presentada al Congreso de la Unión por el Secretario de Estado y del Despacho del Ramo, Lic. Olegario Molina (corresponde al ejercicio fiscal 1909-1910), p. xlvii.

${ }^{41}$ BJLLO, Memoria de la Secretaría de Fomento presentada al Congreso de la Unión por el Secretario de Estado y del Despacho del Ramo, Lic. Olegario Molina (corresponde al ejercicio fiscal 1909-1910), p. xlvii. 
el propósito de atender dos problemáticas básicas: la primera atendía el principal problema de productividad, la vulnerabilidad de los trigos criollos al ataque del chahuistle; la segunda, de índole económica, la limitada producción nacional de trigos duros, lo que obligaba a la industria panificadora a importarlos con frecuencia de Estados Unidos. Una tercera problemática aparentemente no fue prioritaria: la exigua producción de trigo durante el periodo primaveral.

Las primeras introducciones se realizaron a inicios y durante los años más turbulentos de la revolución mexicana. Según Cotter, la Secretaría introdujo entre 1907 y 1912, un total de 107 variedades mejoradas de trigo desarrolladas en Canadá, Estados Unidos, España, Italia y Francia. ${ }^{42}$ Acorde a las prioridades establecidas, se dio preferencia a nuevas variedades de trigos paneros de probada resistencia a las enfermedades fungosas, pero que fuesen específicamente de maduración temprana porque tal rasgo fisiológico interrumpía el desarrollo natural del hongo reduciéndose el daño causado. Las variedades además debían ser resistentes al estrés hídrico, típico de la temporada invernal en México.

Con tales propósitos, la Dirección General de Agricultura en 1912 distribuyó las siguientes variedades entre las principales asociaciones de productores:

[...] según su costumbre, distribuirá para su experimentación, a mediados del mes de septiembre en adelante, muestras de trigos que se recomiendan como inmunes al chahuixtle y [con] resistencia a la sequía. Los trigos que se van a distribuir serán los siguientes: trigo blanco fino del país, resistente al chahuixtle; trigo semi-duro del país resistente al chahuixtle; trigo rojo de Egipto, importado directamente de aquel país, resistente a la sequía y al chahuixtle; trigo rojo de Turquía importado de los Estados Unidos resistente

42 Cotter, "Before the green revolution", p. 64. 
a la sequía y al chahuixtle; trigo gentil rojo semi-duro de iguales propiedades que el anterior; trigo gentil blanco, blando y rendidor; trigo "fielosano" seleccionado, semi duro, resistente al chahuixtle. ${ }^{43}$

Del listado de trigos de alto rendimiento se lograron identificar algunos de ellos: los gentiles, variedades híbridas de trigos duros italianos de probada calidad harinera y altamente resistentes al estrés hídrico. El popular Turkey, ampliamente cultivado en las grandes llanuras de Norteamérica. Fue un trigo duro, rojo y de invierno ("hard red winter”), el cual se había introducido desde Rusia en 1870, y cuidadosamente adaptado para obtener mayor resistencia al estrés hídrico. ${ }^{44}$ Las medidas tomadas por la Secretaría también contemplaron una distribución mucho más amplia y efectiva de algunos de los mejores trigos criollos: aquellos blancos y suaves, altamente productivos y con mayor resistencia a la sequía y al chahuistle, entre ellos, el trigo Sonora. Para 1914, en plena contienda revolucionaria, la Secretaría registraba la participación de 800 agricultores en las tareas de experimentación con nuevas variedades de trigo; $12 \mathrm{t}$ de semillas resistentes se habían distribuido entre los socios de las cámaras agrícolas de León, Guadalajara, Puebla, Querétaro y Aguascalientes; ${ }^{45}$ un equivalente a 200 ha experimentales aproximadamente.

Por su parte, la Estación Central Agrícola ensayaba con nuevas variedades y se probaban su adaptabilidad agroecológica y sus rendimientos, superiores a los trigos locales. Se cultivaron

43 Periódico Oficial del Estado de Querétaro (22 ago. 1912), pp. 329-330. El cálculo de las ha posibles se estimó con relación a 60 kg por ha, la media simple entre 40 y $80 \mathrm{~kg}$, una oscilación que variaba según la región triguera de referencia.

44 Consúltese Olmstead y Rhode, Creating Abundance, cap. 2; Vilmorin, Los trigos y DALRYMPLE, "Changes in wheat varieties".

45 BJLLO, Memoria de la Secretaría de Fomento presentada al Congreso de la Unión por el Secretario de Estado y del Despacho del Ramo, Lic. Leopoldo Rebollar (corresponde al ejercicio fiscal 1912-1913) (1914), p. lxxii. 
algunas de las variedades híbridas más productivas de Francia. Por ejemplo, para atender el grave problema de la exigua producción de trigo durante el periodo primaveral, se experimentó la aclimatación del Japhet, de probada resistencia a las temporadas de lluvias. ${ }^{46}$ Para la obtención de nuevas variedades resistentes al estrés hídrico y las enfermedades se probó la variedad Noé, un trigo de invierno, de maduración precoz y alto rendimiento desarrollado por la empresa semillera Vilmorin y ampliamente cultivado en el suroeste de Francia y noroeste de España. ${ }^{47}$ Se siguió experimentando con los trigos duros desarrollados por las empresas semilleras italianas, como el Gentil Rosso, Rosso Varetto, Rieti, Richielli y blanco de Nápoles, así como la variedad francesa conocida como Belotourca, ${ }^{48}$ que servía tanto para la elaboración de pastas como para la panificación. ${ }^{49}$

No deja de llamar la atención que en los campos experimentales recién montados en los valles de Ciudad Juárez, Chihuahua, y de San Martín, al norte de Nuevo León, se iniciaran las primeras pruebas con variedades egipcias de trigos duros de primavera. Formaban parte de los experimentos para reproducir la

\footnotetext{
46 "Resultados obtenidos", pp. 231-232.

47 Trigo de la Isla de Noé, originario de la comunidad del mismo nombre ubicada al sur de Francia, próxima a la frontera española. También fue conocido como trigo de Aquitania o trigo Azul. Era de granos amarillentos, caracterizado por su maduración precoz, de gran vigor y rendimientos, aunque vulnerable a la roya y al carbón. Vilmorin, Los trigos, p. 31.

${ }^{48}$ El Belotourca era un trigo de color rosado, de maduración precoz, y particularmente resistente tanto al frío como al calor, de ahí que se cultivara en los alrededores de París durante el invierno. A pesar de ser una variedad de trigo durum, su contenido de gluten no era tan alto, por lo que podían también obtenerse excelentes harinas para la panificación. VILMORIN, Los trigos, p. 42. 49 BJLLO, Memoria de la Secretaría de Fomento presentada al Congreso de la Unión por el Secretario de Estado y del Despacho del Ramo, Lic. Olegario Molina (corresponde al ejercicio fiscal 1909-1910), anexos, p. 306, y BJLLO, Memoria de la Secretaría de Fomento presentada al Congreso de la Unión por el Secretario de Estado y del Despacho del Ramo, Lic. Leopoldo Rebollar (corresponde al ejercicio fiscal 1912-1913), anexos, p. 550.
} 
agricultura de secano bajo las técnicas del dry farming, las cuales habían permitido la ampliación de la frontera agrícola cerealera en el medio oeste de Estados Unidos y en la amplia zona pampeana de Argentina a partir de la segunda mitad del siglo XIX. ${ }^{50}$

Habrá que recordar que el proceso de obtención de variedades de alto rendimiento y adaptadas a las condiciones agroecológicas era un proceso lento, atado a los ritmos del ciclo del cultivo, y sustentado en la prueba y el error, por lo que los resultados positivos sólo podrían obtenerse en el mediano plazo, en al menos seis años según Vilmorin, el gran especialista en trigos de la época. En el proceso se presentaban con frecuencia mutaciones, híbridos naturales o ciertos especímenes en los que se presentaban características específicas de sus progenitores no presentes en el resto de la cosecha. De estas variedades espontáneas solían desarrollarse las nuevas de mayor potencial, mediante selección y reproducción controlada. De acuerdo a los reportes de la Estación Agrícola de Río Verde, S.L.P., se habían realizado experimentos "de aclimatación de 11 variedades exóticas con resultados enteramente deficientes”, no obstante:

[...] cuando se hizo la primera cosecha de los trigos 9 y 10 de resistencia efectiva contra el chahuixtle se advirtió que había espigas de dos clases, perfectamente distintas en cada una de esas variedades:

50 Sobre el dry farming, éste consiste en una serie de técnicas de manejo de la humedad de los suelos para retener el material orgánico y la humedad en los escasos periodos de lluvia de las zonas semiáridas mediante el barbecho labrado. Ello fue posible gracias al desarrollo de maquinaria agrícola que hizo posible el labrado en amplias extensiones. Para mayor detalle véanse el informe del IV Congreso de Agricultura de Temporal y los experimentos llevados a cabo en los campos experimentales de Ciudad Juárez y la Granja de San Martín, NL, por Rómulo Escobar. BJLLO, Memoria de la Secretaría de Fomento presentada al Congreso de la Unión por el Secretario de Estado $y$ del Despacho del Ramo, Lic. Leopoldo Rebollar (corresponde al ejercicio fiscal 1912-1913), anexos, pp. 401-408. Para mayor detalle consúltese SunYER, “Temporal y regadío". 
una espiga corta, barba negra y abierta y otra de espiga larga, barba rubia cerrada, en el grano se observaron además diferencias demasiado sensibles en su calidad y cantidad [...] desde ese entonces conservamos con empeño y cuidado con los nombres de A y B en cada variedad, por los excelentes rendimientos que produjeron y por el hecho ya asentado de su real resistencia contra el chahuixtle. ${ }^{51}$

La descripción de este hallazgo en la estación de Río Verde, en San Luis Potosí es una clara muestra de que, en México, el personal técnico había iniciado la búsqueda del fenotipo extremo. En el caso específico del trigo la fisiología arquetípica consistía en desarrollar variedades de tallos más fuertes, granos más gruesos, de mayor vigor y rendimiento.

A partir de la promulgación de la Constitución de 1917, la nueva Secretaría de Agricultura y Fomento realizó un conjunto de reformas sobre los servicios de investigación y extensión agrícolas. La Secretaría absorbió la Estación Agrícola Central y fundó la Dirección de Estudios Biológicos para concentrar los esfuerzos de investigación y experimentación, la cual estuvo a cargo de Alfonso Herrera, considerado el padre de las ciencias biológicas en México. Para lograr una mayor financiación y participación de autoridades y productores locales se establecieron las escuelas regionales y escuelas-granja agrícolas, basándose en los modelos de los servicios de extensión desarrollados por los gobiernos estadounidense y francés. ${ }^{52}$ La respuesta fue relativamente positiva; se abrieron escuelas en Tabasco, Yucatán,

51 "Informe de la Estación Agrícola Experimental de Río Verde", en Periódico Oficial del Gobierno del Estado de San Luis Potosí (23 ago. 1910), pp. 3-4.

52 En ambos modelos se les otorgaba un papel preponderante a la iniciativa privada y a las autoridades públicas locales sobre las actividades de fitomejoramiento de los cultivos; en todo caso, las instituciones centrales figuraban como coordinadoras, auxiliares y promotoras culturales del cambio y las mejoras obtenidas. Tal modelo le venía bien al gobierno federal, pues la precariedad de las finanzas públicas le impedía construir un aparato institucional más amplio, con programas de investigación de mayor alcance. 
Morelos, Guanajuato, Querétaro, Michoacán, entre otras que se estaban planeando. Según Cervantes y Saldaña, fue la razón principal de que los gobiernos estatales perdieran el interés de desarrollar más estaciones experimentales regionales, las cuales cerraron en 1921. En su lugar se abrieron campos experimentales, tanto en las escuelas locales como principalmente en las parcelas que las asociaciones de agricultores destinaron a la experimentación agrícola. ${ }^{53}$

Como se ha señalado, el dominio de la fitotecnia por parte de los agricultores era la clave para el mejoramiento de los cultivos, particularmente para la obtención de líneas puras. Con este propósito la Secretaría lanzó un programa de divulgación, de mucho mayor alcance, sobre las mejores prácticas de selección de semillas por medio de publicaciones científicas, en los periódicos oficiales de cada entidad, así como mediante un conjunto de boletines que la misma Secretaría publicaba con tales fines. ${ }^{54} \mathrm{En}$ tales medios quedaban explicitadas las características fisiológicas del trigo buscadas y que definían el fenotipo extremo del cultivo; así queda constatado, por ejemplo, en El Informador en 1917:

Deben elegirse granos gruesos y de peso y prescindir de aquellos que siendo gruesos no reúnan la segunda condición y resulten bastante ligeros... para verificar una selección concienzuda, se procederá poco antes de la siega, a la recogida de las espigas cuyos pies sean más vigorosos, de tallo largo y paja gruesa; de estas espigas, se elegirán los mejores granos, porque no todos ellos, poseen la misma riqueza ni igual desarrollo y peso, siendo por lo general, los que reúnen mejores condiciones, los situados en el tercer medio,

53 Cervantes y Saldaña, "Las estaciones agrícolas experimentales", p. 320.

${ }^{54}$ Por ejemplo, el Boletín de la Dirección General de Agricultura que fue publicado entre 1911 y 1917; y la Revista Agrícola, que lo sustituyó y que se mantuvo hasta 1921. Cenvantes y SaldaÑa, "Las estaciones agrícolas experimentales", p. 339. 
sin que por esto se deba prescindir de todos los granos de la base ni de los del tercio superior de la espiga [....$^{55}$

Claro está que el público al que se dirigía la divulgación escrita fue el gran productor y no el campesinado, en el que además predominaba el analfabetismo.

Pese a los esfuerzos descritos, fue muy poco o casi nulo el impacto de las variedades exóticas en materia de productividad. Para 1919, la información estadística mostraba que se mantuvieron los mismos rendimientos del periodo porfiriano, con un promedio de media tonelada por hectárea al año (tabla 3). No obstante, si en esos años se registró una fuerte escasez de trigo se debió a la caída de la superficie cosechada y no a los rendimientos, lo que no deja de llamar la atención sobre el potencial productivo de las semillas criollas.

Tabla 3

INDICADORES DEL CULTIVO DEL TRIGO, 1897-1919

\begin{tabular}{lccc}
\hline Años & Superficie (ha) & $\begin{array}{c}\text { Rendimientos } \\
(\mathrm{kg} / \mathrm{ha})\end{array}$ & Producción $(\mathrm{t})$ \\
\hline Promedio, 1897-1912 & 511344 & 569 & 290826 \\
1913 & 107069 & 300 & 32121 \\
1914 & 266666 & 540 & 144000 \\
1915 & 238880 & 500 & 119440 \\
1916 & 247272 & 550 & 136000 \\
1917 & 286792 & 530 & 152000 \\
1918 & 317117 & 555 & 176000 \\
1919 & 336842 & 570 & 192000 \\
1920 & 368141 & 565 & 208000 \\
\hline
\end{tabular}

FuENTE: Estadísticas históricas.

${ }_{55}$ El Informador (16 dic. 1917), p. 2. 
LA SIEMBRA DE SEMILLAS MEJORADAS, EL NORTE TRIGUERO Y LA FITOSANIDAD EN LOS AÑOS VEINTE

Con el establecimiento del nuevo Estado mexicano a partir de 1917 y ante el creciente papel de los ingenieros agrónomos dentro de la Secretaría de Agricultura y en la propia definición de la reforma agraria, se comenzó a promover la "agricultura científica" como el modelo idóneo para resolver el "atraso" del campo mexicano. Si bien fue una época de intensos debates ideológicos sobre el proyecto de modernización agraria, había cierto consenso sobre la importancia de alentar la productividad. ${ }^{56} \mathrm{En}$ líneas generales, se mantuvo la misma estrategia de la década previa: seguir impulsando entre los agricultores la obtención de líneas puras (semillas mejoradas o híbridas), estimular su uso en la siembra, y combatir de una forma más sistemática las principales enfermedades y plagas.

Uno de los cambios más relevantes en la agricultura triguera mexicana fue la planeación y apertura de nuevas tierras agrícolas en las principales cuencas hidrológicas del centro-norte y norte, bajo el liderazgo de la Comisión Nacional de Irrigación a partir de 1926. Primero porque transformó al territorio norteño en un gran campo de experimentación agronómica, en el que se realizaron numerosos estudios para identificar aquellos cultivos con sus correspondientes variedades mejoradas a fin de desarrollar

${ }^{56}$ Incrementar los rendimientos de los cultivos se convirtió en una tarea impostergable para los nuevos grupos en el poder. La alta productividad formaba parte del modelo de agricultura intensiva, el cual buscaba promoverse como solución a la reducida dimensión de los predios promovida por el reparto agrario. En el largo plazo, la productividad era la solución para atender el grave problema de la desnutrición de la mayoría de la población rural. Para una mayor comprensión del papel de los ingenieros agrónomos en la reforma agraria y los planes más amplios de modernización agrícola, consúltese ERvin, "The art of possible". Sobre los debates en torno a la reforma agraria, CотTER, "Before the Green revolution", pp. 59-157, y Troubled Harvest, pp. 49-52; Olea Franco, “One century”, pp. 341-367, 524-541. 
el modelo de agricultura comercial. ${ }^{57}$ Segundo, porque en este extenso territorio se amplió sustancialmente la frontera agrícola triguera.

Respecto al mejoramiento de los servicios de experimentación y extensión, otro de los cambios importantes fue la creación, en 1920, de la figura de los agrónomos regionales. En ellos recayó la responsabilidad de coordinar los proyectos de fitomejoramiento y, en general, todos los servicios de extensión en las 35 áreas agrícolas que se definieron en su momento. ${ }^{58}$ Mas la incapacidad fiscal del Estado para sostener un aparato más amplio fue una constante durante la década de los veinte: en el último año de la presidencia obregonista, el secretario de Agricultura había dejado vacantes 11 posiciones de las 35 planeadas; para 1925, el gobierno callista redujo aún más el número de agrónomos regionales, quedando sólo 20 de ellos en sus posiciones, y concentrándose en las regiones de mayor desarrollo agropecuario y mejor comunicadas..$^{59}$ De nuevo, la participación de

${ }^{57}$ En la revista Irrigación en México (1931-1947) se reportaron algunas de las investigaciones realizadas en los campos experimentales ubicados en las áreas de riego. Por ejemplo, Bancalari, "Posibilidad del cultivo"; Arteaga, "El proyecto de Valle de Juárez"; Departamento Agronómico, "La labor de la granja”; BRAmBILA, "La granja experimental".

${ }^{58}$ La dirección de los servicios estuvo a cargo de dos de los agrónomos más relevantes de la época: Gonzalo Robles (1920-1924), quien concibió la figura de "agrónomo regional" basándose en los servicios de extensión estadounidenses, y Juan A. González, quien perduró en el puesto desde 1925 hasta 1933. Este último estudió en la Universidad Estatal de Iowa, en donde hizo amistad con el futuro secretario de Agricultura y vicepresidente de Estados Unidos, Henry Wallace. CотTER, “Before the green revolution”, pp. 73-75.

59 Según la Memoria de la Secretaría de Agricultura y Fomento (1924-1925), las zonas que quedaron sin cobertura fueron las siguientes: distrito sur del territorio de Baja California, los estados de Sonora, Nayarit, Tabasco, Campeche, Yucatán, Oaxaca, Chiapas, el norte del estado de Veracruz, el territorio de Quintana Roo, la costa del estado de Guerrero y parte del de Durango. BJLLO, Memoria de la Secretaría de Agricultura y Fomento presentada al Congreso de la Unión por el Secretario de Estado y del Despacho del Ramo, 
los agricultores en los programas de fitomejoramiento se tornó indispensable en este contexto de reducción del personal técnico de la Secretaría. Para solventar las limitaciones, los ingenieros agrónomos definieron las principales problemáticas de cada zona y ejecutaron los trabajos de experimentación y de demostración en cooperación con aquellos agricultores "progresistas" que estuvieran dispuestos a financiar la operación experimental.

Posiblemente el avance más relevante durante estos años, y pese a la precariedad presupuestal, fue que se definieron estrategias de fitomejoramiento acordes a los diversos contextos agroecológicos de las zonas trigueras del país, en parte, sustentadas en los resultados de investigación experimental de los años previos. Para los valles del altiplano central mexicano, la Estación Agrícola Central buscaba líneas puras de trigos criollos debido a que habían demostrado rendimientos superiores a las variedades importadas. Por el contrario, en las tierras trigueras del Bajío, en los campos experimentales de Querétaro y Guanajuato, continuaban los trabajos con variedades exóticas para la identificación de aquellas que se adaptaran mejor a las condiciones climáticas locales. La misma práctica se dio en las tierras de riego del norte, en las que se estaba expandiendo el cultivo de trigo. ${ }^{60}$ Con el fin de facilitar el proceso, el gobierno federal alentó la circulación de semillas de alto rendimiento, importadas y nacionales, mediante la exención de derechos aduanales y de fletes en los ferrocarriles. La Secretaría, por ejemplo, registró en 1925 la importación de 400 t de semillas de trigo mejoradas -el equivalente al cultivo de 6500 ha- distribuidas principalmente en "el territorio de Baja California, en Guerrero y Galeana,

Ing. Luis L. de León (corresponde al periodo 1o de agosto de 1924 a 31 de julio de 1925), p. 67.

60 BJLLO, Memoria de la Secretaría de Agricultura y Fomento presentada al Congreso de la Unión por el Secretario de Estado y del Despacho del Ramo, Ing. Luis L. de León (corresponde al periodo 1o de agosto de 1924 a 31 de julio de 1925), p. 66. 
Chihuahua, así como también en los estados de Guanajuato, Aguascalientes y Jalisco". ${ }^{61}$

Lo importante a destacar es que estas iniciativas estimularon la demanda de semillas de mayor potencial para la siembra. Tal cambio se dio con mayor intensidad en las zonas de riego del norte, principalmente en Mexicali y la Comarca Lagunera. La siembra de semillas mejoradas formó parte del proceso de experimentación que los agricultores llevaron a cabo para implementar un sistema de rotación de cultivos y así diversificar el monocultivo algodonero (algodón en verano-trigo en invierno). Durante el segundo quinquenio de la década de1920 se tiene registro de que en las tierras laguneras se introdujo con relativo éxito el Candeal, una variedad mejorada de trigo duro blanco, la cual, junto con otras variedades criollas, fue cultivada en una extensión aproximada a las 30000 ha. Posiblemente dicha variedad fue desarrollada en España, pues predominaba en buena parte de las zonas trigueras de la península Ibérica, debido a la gran calidad de las harinas obtenidas y su probada resistencia a la aridez. Dada la escasez permanente de trigos duros en el mercado nacional, el Candeal lagunero se comercializó con gran facilidad en las principales agroindustrias de Saltillo y Monterrey, que lo mezclaban con trigos blandos para la elaboración de panes. ${ }^{62} \mathrm{El}$

${ }^{61}$ El gobierno federal, mediante la Secretaría de Comunicación y Obras Públicas, autorizó "el flete libre por express para semillas en cantidades no mayores de $10 \mathrm{~kg}[\ldots]$ quedando sujetos a tarifa especial reducida los embarques de los mismos artículos en carro por entero". Además de semillas de cereales, la exención también abarcó árboles, bulbos y caña para semilla en envíos con peso máximo de $100 \mathrm{~kg}$. BJLLO, Memoria de la Secretaría de Agricultura y Fomento presentada al Congreso de la Unión por el Secretario de Estado y del Despacho del Ramo, Ing. Luis L. de León, (1을 de agosto de 1924 a 31 de julio de 1925), p. 70.

${ }^{62}$ Sobre el trigo en la Comarca Lagunera, Rivas, "Cambio tecnológico", cap. 2. No obstante, el problema de la baja producción nacional de trigos duros seguía causando serias confrontaciones entre productores e industriales harineros, tal como puede constatarse en la Memoria de la Secretaría. BJLLO, Memoria de la Secretaría de Agricultura y Fomento presentada al Congreso de 
sistema de rotación de cultivos en ambas regiones algodoneras finalmente se consolidó en las siguientes tres décadas.

La creciente circulación de semillas en los años veinte, empero, agudizó las epifitias debido a que tanto semillas como costales y vagones del ferrocarril solían contaminarse con huevecillos, parásitos y hongos microscópicos. Pero también porque en México no se habían establecido reglamentos oficiales que exigieran controles fitosanitarios en el embalaje y transportación de productos agrícolas, tal como se venía practicando en Estados Unidos desde principios del siglo pasado. ${ }^{63}$ Tales circunstancias obligaron a la Secretaría a desarrollar programas más eficaces en materia de fitosanidad. En 1924, se promulgó la primera Ley de Plagas, el instrumento idóneo para hacer cumplir las campañas nacionales que buscaban proteger las zonas agrícolas "contra invasiones de plagas y enfermedades procedentes del extranjero y de regiones infestadas existentes dentro del propio país". En 1927, se creó la Oficina para la Defensa Agrícola y se estableció el Reglamento de Policía Sanitaria Agrícola. ${ }^{64}$ Con este mayor soporte jurídico e institucional se establecieron, en ese mismo año, las primeras cuarentenas exteriores y se intensificaron las campañas de desinfección de semillas previo a la siembra, campaña que estuvo a cargo de los agrónomos regionales y fue

la Unión por el Secretario de Estado y del Despacho del Ramo, Ing. Luis L. de León (1o de agosto de 1924 a 31 de julio de1925), p. 70.

${ }^{63}$ De hecho, desde 1912, el departamento de agricultura del país vecino instauró una cuarentena federal que prohibió las importaciones de frutas procedentes de México por el problema de la plaga de la mosca de la fruta, medida que afectó profundamente a la fruticultura comercial mexicana. RIvas, "La constitución”, p. 152.

${ }^{64}$ Senasica, La presencia de la sanidad vegetal, pp. 8-9. A la Oficina de Defensa Agrícola le anteceden la Sección de Parasitología, creada en 1915, la cual sustituyó a su vez a la antigua Comisión Nacional de Parasitología, la primera institución estatal en materia de fitosanidad, fundada en 1900. Para mayor detalle consúltese Rivas, “La constitución”, p. 153. 
difundida por la Secretaría en los periódicos oficiales de cada entidad.

En el caso del trigo fueron las enfermedades fungosas las que había que atender con urgencia y lo hicieron mediante dos vías: la desinfección de semillas y la resistencia biológica del cultivo. Para ese entonces, la investigación biológica demostraba ya avances importantes sobre la etiología de las principales fitopatologías del trigo, lográndose distinguir con claridad el ciclo de desarrollo del chahuistle, del tizón y del carbón, como se les nombraba comúnmente, enfermedades que los agricultores solían confundir. Según una publicación de la Secretaría en 1928, después del chahuistle, era el tizón el que ocasionaba las mayores pérdidas en las cosechas, las cuales se estimaban entre 30 y hasta 60 \% según la zona; le seguía el carbón, con una afectación estimada de $2 \%$ del total cosechado. ${ }^{65}$ Para prevenir las infestaciones de tizón y de carbón se recomendaba desinfectar las semillas. En el primer caso mediante la sumersión en soluciones de formalina o de sulfato de cobre, aunque se recomendaba el uso de carbonato de cobre, pues resultaba mucho más sencillo de manejar, además de potenciar el poder germinativo de las semillas. Para atender el carbón bastaba con sumergir las semillas en agua caliente. Sin embargo, la desinfección de las semillas y los fungicidas de la época no funcionaban con el chahuistle. La única alternativa posible era el desarrollo de variedades con mayor resistencia a la enfermedad. La Secretaría continuó introduciendo variedades exóticas de probada resistencia, tales como la Kansas Red, de origen estadounidense, la cual además era "rendidora, precoz y resistente al frío, y de iguales cualidades para la molienda y la panificación a los trigos duros rojos". ${ }^{66}$

65 "Las enfermedades más comunes del trigo", Secretaría de Agricultura, en Periódico Oficial del Estado de Hidalgo (16 feb. 1928), p. 53.

66 "Las enfermedades más comunes del trigo", Secretaría de Agricultura. Periódico Oficial del Estado de Hidalgo (16 feb. 1928), p. 54. El Kansas Red posiblemente sea una línea nueva procedente del Turkey, el cual, tanto en Kansas 
Como complemento, los agrónomos regionales incentivaron a los agricultores a eliminar las plantas silvestres en los alrededores de las zonas de plantío, ya que éstas favorecían la propagación de la enfermedad. ${ }^{67}$ Una tarea, por cierto, muy poco adoptada.

$\mathrm{Al}$ final de los años veinte, los esfuerzos realizados en el mejoramiento del cultivo y, en general, en materia de sanidad vegetal dieron sus primeros frutos. Posiblemente sean los principales cambios identificados que contribuyeron al incremento de $15 \%$ de los rendimientos del trigo y de $13 \%$ del volumen de producción total registrado en la década, si se compara con el periodo porfiriano (véase la tabla 4). A favor de este argumento está el hecho de que la superficie cultivada registró un incremento marginal de $1.5 \%$, casi estable en las 500000 ha desde 1897, y que la incorporación de maquinaria en las labores agrícolas era aún incipiente en la época.

\section{Tabla 4}

INCREMENTOS EN LOS PRINCIPALES INDICADORES

DEL CULTIVO DE TRIGO, 1897-1930

\begin{tabular}{lcccccc}
\hline Periodo & $\begin{array}{c}\text { Superficie } \\
\text { (ba) }\end{array}$ & $\begin{array}{c}\text { Dif. } \\
\%\end{array}$ & $\begin{array}{c}\text { Rendimiento } \\
(\mathrm{kg})\end{array}$ & $\begin{array}{c}\text { Dif. } \\
\%\end{array}$ & $\begin{array}{c}\text { Producción } \\
(\mathrm{t})\end{array}$ & $\begin{array}{c}\text { Dif. } \\
\%\end{array}$ \\
\hline $1897-1912$ & 495879 & & 570 & & 279975 & \\
$1921-1930$ & 503123 & 1.5 & 656 & 15.1 & 316248 & 13.0 \\
\hline
\end{tabular}

FuENTE: elaboración propia con base en Estadísticas históricas.

Nota: dadas las fluctuaciones anuales en los indicadores, se optó por estimar la mediana de cada periodo y no la media simple.

De la tabla previa, resaltan los rendimientos obtenidos en la década, con una media de $636 \mathrm{~kg} / \mathrm{ha}$ (un incremento de $15 \%$ ).

como en el resto de las grandes llanuras de Estados Unidos, fue la variedad predominante durante la primera mitad del siglo pasado.

${ }^{67}$ Las enfermedades fungosas se propagaban mediante la acción del viento, el cual esparcía los hongos microscópicos a kilómetros a la redonda. 
Tal productividad del cultivo fue semejante a lo obtenido en Italia (635-711 kg/ha) y muy superior a la de España (408-457 $\mathrm{kg} / \mathrm{ha}$ ), es decir, de los países donde se importó buena parte del material genético para el mejoramiento del cultivo (revísese la tabla 1). Eso nos lleva a pensar en una supuesta superioridad de los trigos criollos frente a los híbridos y mejorados de otras latitudes, pues todavía en estos años se seguían cultivando ampliamente en las regiones tradicionales trigueras.

Sin embargo, un incremento de $13 \%$ del volumen total de la producción nacional, el equivalente a algo más de 36000 t, resultó una cifra bastante modesta para las necesidades de la época. Las $316000 \mathrm{t}$ promedio anuales resultaron insuficientes para cubrir la demanda interna, estimada en un promedio de 410000 t para el segundo quinquenio de la década de $1920 .{ }^{68} \mathrm{Si}$ los alcances de las innovaciones biológicas no fueron mayores, en parte puede explicarse por el impacto negativo de las nuevas prácticas de fitomejoramiento en la relación costo-precio del cultivo, ya que los márgenes de rentabilidad en la agricultura extensiva de los alimentos básicos eran bastante más bajos en comparación con otros cultivos que también fueron sujeto de programas de fitomejoramiento (véase la tabla 5). Posiblemente ello propició que las innovaciones biológicas se concentraran en las grandes haciendas trigueras, dejando al margen a la mayoría de los pequeños productores y comunidades dedicadas al cereal. Mas no habría de desestimarse la importancia del capital social, es decir, de la capacidad de negociación y coordinación entre los agricultores de cada localidad, tanto para las pruebas experimentales como para el combate de las enfermedades. ${ }^{69}$

\footnotetext{
68 Rodríguez, Producción y consumo, p. 35.

69 Bastaba, por ejemplo, que algún productor no realizara las medidas preventivas contra el chahuistle para que éste se propagara con gran rapidez en los campos aledaños y se perdieran, en los casos más graves, las cosechas a nivel regional.
} 


\section{Tabla 5}

ESTIMACIONES DE RENTABILIDAD DE LOS PRINCIPALES

CULTIVOS, 1929

\begin{tabular}{lcc}
\hline Cultivo & $\begin{array}{c}\text { Rentabilidad } \\
\text { (pesos/ha) }\end{array}$ & $\begin{array}{c}\text { Superficie cosechada } \\
\text { ( ha })\end{array}$ \\
\hline Frijol & 18 & 733421 \\
Cebada & 21 & 160824 \\
Maíz & 38 & 2865119 \\
Trigo & 80 & 520771 \\
Garbanzo & 82 & 108899 \\
Algodón & 210 & 198938 \\
Jitomate & 383 & 29054 \\
Caña de azúcar & 386 & 69831 \\
\hline
\end{tabular}

FuENTE: Estadísticas históricas.

Nota: pesos corrientes.

\section{LA SUPERIORIDAD DE LOS TRIGOS Y CIERTOS PATRONES REGIONALES EN LOS AÑOS TREINTA}

Al igual que el resto de las actividades productivas en México, la economía triguera resintió profundamente los efectos de la gran depresión. El desplome de las importaciones de trigo de Estados Unidos con las cuales se completaba la demanda nacional provocó la caída del consumo per cápita del cereal, de por sí bajo, en una proporción aproximada a los $4 \mathrm{~kg}$, al caer de 26.3 a $22.3 \mathrm{~kg}$ (véase la tabla 6). Dicho de otra forma, el consumo medio mensual por persona estimado fue de $1.85 \mathrm{~kg}$, nada más lejano que lo planeado por los especialistas de la Secretaría, algunos de los cuales buscaban incluso sustituir el maíz por el trigo en la dieta del campesinado. ${ }^{70}$

70 Bajo la influencia de las ideas eugenésicas en boga, así lo declaraba el agrónomo Francisco Quintanar, quien promulgaba que había de "liberarse de la esclavitud del maíz” que hizo a los “indígenas negligentes”. El debate sobre los pobres aportes nutricionales de la tortilla de maíz fue impulsado por 
Tabla 6

ESTIMACIONES SOBRE EL CONSUMO NACIONAL DE TRIGO

\begin{tabular}{lccc}
\hline Periodo & $\begin{array}{c}\text { Consumo } \\
\text { per cápita }\end{array}$ & $\begin{array}{c}\text { Consumo } \\
\text { nacional }(t)\end{array}$ & $\begin{array}{c}\text { Importaciones } \\
(t)\end{array}$ \\
\hline $1925-1929$ & 26.38 & 410153 & 61961 \\
$1930-1934$ & 23.94 & 411225 & 20311 \\
$1935-1939$ & 22.29 & 417866 & 29169 \\
\hline
\end{tabular}

Fuente: RodRíGuez, Producción y consumo.

Las sequías y las plagas agudizaron la escasez de alimentos básicos. Tal escenario provocó que la autosuficiencia alimentaria fuese una meta urgente e impostergable, incluyéndose en este propósito la producción de trigo. No obstante, la precariedad de las finanzas públicas comprometió aún más el funcionamiento del aparato estatal en materia de fomento agrícola. De nuevo, los servicios de investigación y extensión sufrieron una profunda reforma, pero con el mismo propósito: aumentar la participación y financiación de los productores en los programas de fitomejoramiento. En 1932, se crearon el Consejo Nacional de Agricultura y los consejos locales de fomento agrícola con el fin de consolidar la organización de los agricultores, tanto privados como ejidales, y favorecer una coordinación más estrecha con las instituciones públicas de fomento. ${ }^{71}$ Asimismo, las limitaciones presupuestales obligaron a la Secretaría a reducir aún más el número de agrónomos regionales, quedando sólo 11 de

intelectuales tan importantes como Manuel Gamio y sostenido por Enrique Beltrán, director del Instituto Biotécnico, quienes promovieron el consumo del pan para "mejorar la condición racial de nuestra gente". CоTtER, Troubled Harvest, p. 92.

${ }^{71}$ Para mayor detalle, BJLLO, Memoria de la Secretaría de Agricultura y Fomento presentada al Congreso de la Unión por el Secretario de Estado y del Despacho del Ramo, Lic. Francisco S. Elías (1- de agosto de 1932 al 31 de julio de 1933). 
ellos en sus puestos en 1932. Su recuperación no se daría sino hasta el cierre de la década, cuando aumentó su número a 19. ${ }^{72}$ En compensación, la reforma creó a los promotores agrícolas, la nueva figura de los servicios de extensión que se les dio a los agricultores involucrados en los programas de fomento. Se sumaron al esfuerzo los gobiernos municipales y el personal técnico del Banco Nacional de Crédito Agrícola. ${ }^{73}$ Promotores y agrónomos continuaron las labores de demostración.

El departamento de agronomía de la Secretaría siguió coordinando a nivel nacional las labores de investigación en los diversos campos experimentales del país. Se continuaron los experimentos de aclimatación de nuevas variedades y de obtención de líneas puras, como se venía practicando. No obstante, la información histórica a la que se ha accedido indica la realización de estudios más acuciosos sobre las relaciones planta-suelo y planta-clima, para atender las especificidades de cada región y, por supuesto, con el fin de elevar la productividad de las variedades a prueba. Destacan las estaciones que se fundaron en el marco de la planeación y desarrollo de los distritos de riego. A las nuevas estaciones agrícolas de Briseñas, Michoacán, y de Celaya, Guanajuato, para el Bajío se le sumó, en 1932, la del río Yaqui, gracias a la colaboración y financiamiento del estado de Sonora, la primera del noroeste de México y posterior epicentro de la revolución verde. Para 1938, la Secretaría reportaba la operación de 11 campos experimentales directamente a su cargo. ${ }^{74}$

72 BJLLO, Memoria de los trabajos ejecutados por las direcciones de Agricultura y Ganadería e Instituto Biotécnico (del año 1935 a mayo de 1940 y dentro del periodo presidencial del Gral. Lázaro Cárdenas), pp. 20-21.

73 Cотter, "Before the green revolution", p. 77.

${ }^{74}$ Los cuales se encontraban ubicados en los lugares siguientes: León, Gto.; Querétaro, Qro.; Valle del Yaqui, Son.; Acapulco, Gro.; Oaxaca, Oax.; Briseñas, Mich.; Tlalnepantla, Méx.; Tapachula, Chis; Kala, Campeche; Villahermosa, Tab.; y Tecax, Yucatán. BJLLO, Memoria de la Secretaría de Agricultura y Fomento presentada al Congreso de la Unión por el Secretario de Estado y 
Varios cambios relevantes se dieron en el marco de esta reforma. Uno de ellos fue la creación de los campos experimentales dedicados exclusivamente al mejoramiento de trigo. Si bien en la Memoria de la Secretaría no se indica el nombre de las semillas, sí reportaba en 1933 la experimentación con 50 variedades de trigos de Italia y Estados Unidos; en la mayoría de ellos, reportaba la institución, "se han podido destacar ya de 10 a 15 variedades de las 50 que se han ensayado". ${ }^{75}$ Para 1938 , se encontraban en operación 23 campos de trigo, 9 de ellos en colaboración con particulares y otras instituciones de fomento. ${ }^{76}$

Otro de los cambios a destacar fue la creación de los campos de multiplicación de semillas mejoradas, con los que se buscaba reproducir a gran escala, y bajo técnicas de control estadístico, el nuevo material obtenido de las experimentaciones. No fue un cambio menor. Hasta ese momento no se habían logrado consolidar las técnicas de fitomejoramiento entre los agricultores y continuaba la pérdida de las cualidades agronómicas de las semillas mejoradas en la resiembra. Con esta iniciativa, por un lado, se pretendió liberar a la mayoría de los productores de tan importante responsabilidad, a la vez que garantizarles la siembra con semillas altamente productivas mediante su distribución gratuita o comercial. Por el otro, que el cuerpo de especialistas de la Secretaría, trabajando coordinadamente con un grupo seleccionado de agricultores, tuviera un mayor control y una supervisión estricta del proceso de reproducción, el proceso clave para estabilizar las cualidades obtenidas de las semillas.

del Despacho del Ramo, Dr. José G. Parres (septiembre de 1938 a agosto de 1938), p. 75.

75 BJLLO, Memoria de la Secretaría de Agricultura y Fomento presentada al Congreso de la Unión por el Secretario de Estado y del Despacho del Ramo, Lic. Francisco S. Elías (10- de agosto de 1932 al 31 de julio de 1933), pp. 112-114. ${ }^{76}$ BJLLO, Memoria de la Secretaría de Agricultura y Fomento presentada al Congreso de la Unión por el Secretario de Estado y del Despacho del Ramo, Dr. José G. Parres (septiembre de 1937 a agosto de 1938), p. 76. 
Gracias a estas iniciativas, la Secretaría anunciaba, en 1935, que en el Bajío se había propagado y extendido el uso de nuevas variedades de trigo de excelente calidad y resistentes al chahuistle. ${ }^{77}$ Aparentemente, cada vez hubo menos necesidad de importarlas al haber mayor disposición en el mercado interno.

Por último, se ampliaron los campos de demostración y ensayo, creándose los campos cooperativos en las comunidades y ejidos, los cuales aumentaron su número hasta llegar a un total de 567 en $1933 .{ }^{78}$

Dentro de estos campos se tiene registro de otros cambios relevantes en materia de fitomejoramiento. En ellos se siguió promoviendo la selección de semillas entre los agricultores, pero ahora insistiendo en la necesidad de sembrar una sola variedad para evitar así el deterioro del material genético a causa de la polinización cruzada entre distintas variedades cultivadas en un mismo campo. Además, se establecieron otras prácticas relacionadas con la reproducción y distribución de las nuevas variedades: las pruebas de germinación de las semillas y los nuevos requerimientos para su mejor almacenamiento. Al respecto, se sabía que el problema fundamental se debía "a que los agricultores cosechan antes de tiempo, por los temores que se tienen de

77 Según la Secretaría, “en la actualidad, las únicas semillas que más se importan son las de papa, que como no alcanza su ciclo vegetativo, tiene que cosecharse antes de que empiecen las lluvias; ... la de trigo, que se utiliza principalmente en las siembras que se hacen en Baja California; y la de algodón, que cada año se tienen que traer del extranjero porque la cosecha en una temporada no puede utilizarse en las siembras de la siguiente por estar infestada con gusano rosado". BJLLO, Memoria de los trabajos ejecutados por las direcciones de Agricultura y Ganadería e Instituto Biotécnico (del año 1935 a mayo de 1940 y dentro del periodo presidencial del Gral. Lázaro Cárdenas), p. 29.

78 La Secretaría reportaba la distribución de 3232 t de diversas semillas mejoradas en un total de 6000 lotes con el propósito de mejorar los cultivos existentes e introducir otros nuevos. BJLLO, Memoria de la Secretaría de Agricultura y Fomento presentada al Congreso de la Unión por el Secretario de Estado y del Despacho del Ramo, Lic. Francisco S. Elías (1 de agosto de 1932 al 31 de julio de 1933), p. 120. 
los daños y efectos que causan las lluvias, que son las que hacen que las semillas se nazcan". ${ }^{79}$ En pocas palabras, las condiciones climáticas limitaban las nuevas prácticas culturales.

Para reforzar el cambio de prácticas culturales entre los agricultores se emitieron dos decretos presidenciales que obligaban a refaccionar a los bancos Nacional de Crédito Ejidal y Nacional de Crédito Agrícola y a dar preferencia en la distribución del agua a la Comisión Nacional de Irrigación a aquellos que habían realizado la selección y desinfección de las semillas. Según las estimaciones del cuerpo técnico de la Secretaría estas prácticas lograban aumentar la productividad de 30 a 50\%, y a la vez reducir drásticamente el ataque del carbón y la carie. ${ }^{80}$

Para la década de los treinta, la experiencia acumulada en materia de aclimatación y mejoramiento del trigo arrojaba ya resultados confiables: a) la superioridad de un grupo selecto de trigos criollos -suaves en su mayoría- sobre el resto de las variedades exóticas que se habían estado introduciendo desde 1909; y b) los híbridos duros rojos de origen italiano -como el Mentana- frente a otras variedades exóticas y nacionales. La investigación experimental se focalizó en estos dos grupos; sobre los primeros continuó su aclimatación a las diversas zonas del país, sobre los segundos, para incrementar sus rendimientos y resistencia al chahuistle.

Una muestra de ellos son los resultados obtenidos entre 1932 y 1935 en el campo experimental del sistema de riego núm. 1 "Presidente Calles", en Aguascalientes, tal como puede

\footnotetext{
79 Según el informe del responsable del sistema de riego No. 1 "Presidente Calles", las pruebas de germinación de la semilla debían registrar como mínimo un poder germinativo de $70 \%$. "El costo de la semilla necesaria para la unidad de superficie el año pasado fue de 10 pesos y en el presente de 9.90 costando su cura por el método seco y a base de USPULUN 0,31". Peña, "Cultivo de trigo", p. 67.

80 BJLLO, Memoria de los trabajos ejecutados por las direcciones de Agricultura y Ganadería e Instituto Biotécnico (del año 1935 a mayo de 1940 y dentro del periodo presidencial del Gral. Lázaro Cárdenas), p. 12.
} 
observarse en la tabla 7. De los 28 trigos sometidos a experimentación, los híbridos italianos ofrecieron los rendimientos más altos que oscilaban entre 1 y $2.5 \mathrm{t} / \mathrm{ha}$; por su parte, los criollos alcanzaban entre 0.80 y $1.3 \mathrm{t} / \mathrm{ha}$, destacándose los colorados de San Antonio, Barbón y Pelón. Cifras y variedades semejantes se reportaban en otros campos experimentales. ${ }^{81}$ Cabe resaltar que los estudios edafológicos se volvieron indispensables en la época para determinar los rendimientos de las distintas variedades, tal como se constata en este mismo informe, en el que se aclaraba: "se prefieren todas aquellas tierras "fuertes" para la siembra de la variedad denominada 'trigo colorado' [variedad criolla] y aquellas menos fuertes para la variedad denominada 'trigo italiano"”. 82

La excepción a la apuesta por los trigos italianos y criollos mejorados fue el éxito de la introducción del trigo Marquis ("red hard spring wheat"), un híbrido desarrollado en Canadá a principios del siglo pasado y que causó una verdadera revolución agrícola en la amplia zona que integra la frontera entre dicho país y Estados Unidos en las primeras décadas del siglo pasado. La variedad se aclimató con facilidad en el Bajío, en particular en algunas zonas de los estados de Querétaro, Guanajuato y Jalisco "con magníficos resultados sobre las variedades ya existentes". ${ }^{83}$ El Marquis mostró superioridad en rendimientos y calidad harinera que los trigos criollos rojos (o colorados), los cuales fueron muy pronto sustituidos en amplias zonas de sembradío. ${ }^{84}$

${ }^{81}$ Consúltense los informes de los campos experimentales en BJLLO, Memoria de la Secretaría de Agricultura y Fomento presentada al Congreso de la Unión por el Secretario de Estado y del Despacho del Ramo, Dr. José G. Parres (septiembre de 1936-agosto de 1937).

82 PeÑa, "Cultivo de trigo", p. 62.

83 BJLLO, Memoria de los trabajos ejecutados por las direcciones de Agricultura y Ganadería e Instituto Biotécnico (del año 1935 a mayo de 1940 y dentro del periodo presidencial del Gral. Lázaro Cárdenas), p. 21.

${ }^{84}$ CotTer, Tronbled Harvest, pp. 80-84. 
Tabla 7

RENDIMIENTO DE HÍBRIDOS ITALIANOS Y CRIOLLOS EN LA ESTACIÓN EXPERIMENTAL DE AGUASCALIENTES. 1932-1935

\begin{tabular}{|c|c|c|c|}
\hline Variedad & $\begin{array}{c}\mathrm{Kg} / \mathrm{ha} \\
(1001- \\
2500 \mathrm{~kg})\end{array}$ & Variedad & $\begin{array}{c}\mathrm{Kg} / \mathrm{ha} \\
(500- \\
1000 \mathrm{~kg})\end{array}$ \\
\hline Gentil rojo núm. 49 & 2480 & Cristalino de Monclova & 932 \\
\hline Mentana & 2480 & Chihuahua núm. 2 & 928 \\
\hline Vittorio veneto & 2280 & Rojo de Piedras Negras & 916 \\
\hline Rutti núm. 11 & 2160 & Maravilla de Chapingo & 884 \\
\hline Cencelli & 1960 & Norteño de Coahuila & 880 \\
\hline Carlota strampelli & 1760 & Breve de Jalisco & 876 \\
\hline Cologna larga & 1560 & Rojo de Torreón, Coah. & 860 \\
\hline Virgilio & 1440 & Cristalino de Jalisco & 852 \\
\hline Edda & 1400 & $\begin{array}{l}\text { Pelón blanco } \\
\text { de Chapingo }\end{array}$ & 840 \\
\hline $\begin{array}{l}\text { Colorado pelón } \\
\text { de San Antonio }\end{array}$ & 1296 & Early beart (EUA) & 828 \\
\hline $\begin{array}{c}\text { Colorado barbón } \\
\text { de San Antonio }\end{array}$ & 1212 & Chapingo núm. 1 & 820 \\
\hline $\begin{array}{l}\text { Pelón colorado } \\
\text { de Chapingo }\end{array}$ & 1164 & $\begin{array}{l}\text { Colorado de riego } \\
\text { de Jalisco }\end{array}$ & 696 \\
\hline Barbón chico de Chapingo & 1160 & & \\
\hline Cologna venetta & 1120 & & \\
\hline Candeal de Coahuila & 1020 & & \\
\hline Blanco de Santiago & 1016 & & \\
\hline
\end{tabular}

Fuente: PeÑa, “Cultivo de trigo", p. 62.

En rasgos generales, para el segundo quinquenio de la década de 1930 se mostraban ya ciertos patrones regionales respecto a las variedades cultivadas. En el norte continuaba la expansión de la frontera triguera mediante variedades exóticas de trigos duros de primavera que mostraban una gran resistencia al estrés hídrico de las zonas desérticas. Esto se presentó con mayor intensidad en el noroeste del país, especialmente en Mexicali, donde se les utilizaba para la siembra, en lugar de destinarlas para desarrollar nuevas variedades adaptadas a las condiciones agroclimáticas 
locales. Al respecto, entre 1936 y 1939, la Secretaría emitió 34 permisos de importación de semillas, libre de derechos, solicitados por agricultores, asociaciones agrícolas y distintas compañías que refaccionaban a un gran número de ejidatarios y pequeños agricultores. Tan solo en 1938 se importaron $2862 \mathrm{t}$ para el cultivo aproximado de 47700 ha. ${ }^{85}$ No obstante, los agricultores de otras zonas norteñas habían logrado mejorar algunos trigos criollos de alta productividad, tales como el Barrigón, Obregón Colorado y Aguilera en Sonora, y el Lagunero y Torreón en la Comarca Lagunera, de uso muy extendido. En el norte, por lo tanto, se consolidaba el cultivo con dos modalidades predominantes respecto al sistema de cultivos: en Mexicali y la Comarca Lagunera, con algodón en primavera-verano y trigo duro o semolero en otoño-invierno; en Sonora y Sinaloa, con oleaginosas en primavera-verano, y trigo duro en otoño-invierno.

Por otra parte, en las tradicionales tierras trigueras del Bajío se cultivaban los criollos, suaves y duros, los duros de origen italiano y el excepcional Marquis. Destacó la aclimatación de las variedades Mentana, Marroquí y el Marquis, así como la variedad criolla conocida como Querétaro. Todos ellos con mayor resistencia al chahuistle y de maduración temprana, para prevenir y reducir en lo posible las enfermedades fungosas. En la mayoría de las tierras de la región predominaba el sistema de cultivos con el maíz en la temporada primavera-verano y el trigo en la temporada otoño-invierno.

En el altiplano central se prefirieron los criollos paneros suaves, con los cuales se seguía trabajando para obtener nuevas líneas puras, pues la mayoría de las variedades exóticas introducidas no lograron superar en rendimiento a los nativos.

85 Particularmente en Mexicali, Tecate, Ensenada y Tijuana en Baja California, y Agua Prieta y Frontera, en Sonora. BJLLO, Memoria de los trabajos ejecutados por las direcciones de Agricultura y Ganadería e Instituto Biotécnico (del año 1935 a mayo de 1940 y dentro del periodo presidencial del Gral. Lázaro Cárdenas), pp. 28-29. 
No obstante, se seguía experimentando con algunos trigos de primavera para continuar evaluando la posibilidad de cultivar el cereal en la temporada primavera-verano, aunque con resultados muy pobres. En la estación experimental central se estaban reproduciendo los trigos criollos Sonora y Cabeza Grande, así como la variedad francesa Noé. Un punto interesante a destacar sobre esta región es que, por efecto de las investigaciones y las recomendaciones hechas por el cuerpo técnico de la Secretaría, comenzó a sustituirse la siembra de maíz por la del trigo de temporal, puesto que éste último exigía menos humedad (véase el mapa 3). En general, en las zonas de sembradío de montaña se promocionaba el cultivo de la cebada en primavera-verano y los trigos duros en otoño-invierno.

Asimismo, si bien para esos años todavía no se había logrado acabar con las epifitias causadas por el chahuistle, había ya una mayor comprensión sobre la complejidad de la enfermedad. El cuerpo de especialistas de la Secretaría había identificado ciertos patrones regionales sobre el grado de desarrollo del ataque fungoso, los cuales dependían del tipo de raza del chahuistle y de la variedad del trigo, pero principalmente de las características agroclimáticas de cada región triguera. Así lo recordaba el propio secretario de Agricultura y Fomento:

Sospechábamos que podrían formar varias zonas caracterizadas por la presencia de diversas formas fisiológicas del chahuixtle y habíamos observado que en la mesa central en un gran triángulo cuyo vértice sería la ciudad de Puebla y cuya base estaría formada por una línea que fuera aproximadamente desde la sierra de Tapalpa, en Jalisco, hasta Aguascalientes, el trigo "Márquis" se comportaba como resistente al chahuixtle en tanto que al norte de esa zona no se comportaba bien $[\ldots] .{ }^{86}$

86 BJLLO, Informe de la Secretaría de Agricultura y Fomento (1942-1943), p. 55. 


\section{Mapa 3}

PRINCIPALES REGIONES TRIGUERAS EN MÉXICO

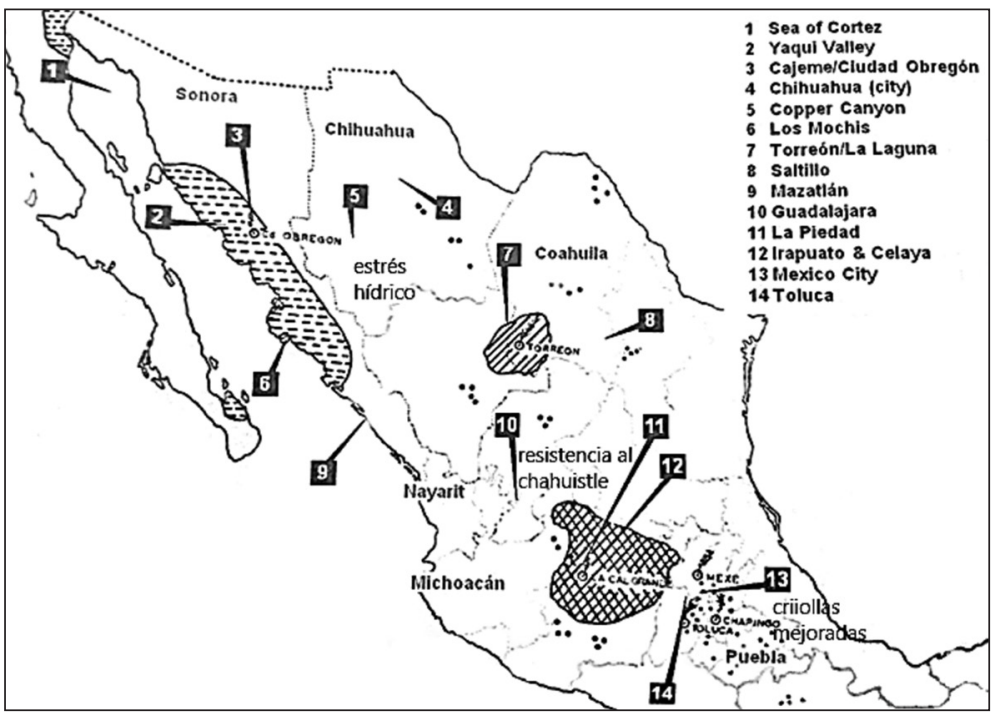

FuENTE: reproducción original. Informe de la Oficina de Estudios Especiales, Secretaría de Agricultura y Fomento, RFA, fondo 126.13, serie 1.1, c. 32, exp. 355, s.f., 1945.

Este hallazgo no era menor. Una de las principales incógnitas de la época para las autoridades de la Secretaría eran los distintos grados de resistencia a la enfermedad de una misma variedad mejorada. ¿Por qué variaban drásticamente según la zona en la que se sembrara? Habían descubierto que ello se debía, en parte, a que las variedades mejoradas eran resistentes a determinadas razas del chahuistle y no a todas en su conjunto, y en México existía un gran número de razas fisiológicas agrupadas en tres tipologías: el negro del tallo (Puccinia graminis tritici), el rayado (Puccinia glumarum) y el de la hoja (Puccinia triticina), el primero el más extendido y dañino en el país. Para inicios de la década de 1940, llegaron a esta conclusión: 
[las] dos grandes áreas trigueras del país -el Norte y la Mesa Central- están pobladas por razas distintas de chahuixtle [del negro del tallo]. De esta manera, el mejoramiento del trigo en esas dos áreas debe ser tratado como dos problemas diferentes, pues las variedades mejoradas para un área serán inadecuadas para la otra [...] El chahuixtle de la hoja y el chahuixtle rayado del trigo, no han alcanzado nunca la importancia del chahuixtle del tallo, pero los dos tipos son comunes en México y en ciertos años, algunas variedades susceptibles pueden ser seriamente dañadas. La eliminación de las variedades altamente susceptibles servirá para limitar los daños de estos dos patógenos. ${ }^{87}$

Como puede observarse, dentro de la Secretaría se reconocía la imposibilidad de obtener una sola variedad superior (el fenotipo extremo) que tuviera los mismos comportamientos de resistencia y productividad para todas las zonas agroclimáticas del país. En consecuencia, la investigación experimental a cargo del Estado debía ser de mucho mayor alcance y constancia, ante la evidente complejidad de los fenómenos naturales. Fue, de hecho, uno de los principales criterios que llevó a la Secretaría a firmar el convenio de colaboración científica con la Fundación Rockefeller. Mientras tanto, en la práctica, se observó que las condiciones más extremas de aridez y de calor del territorio norte mermaban el desarrollo de las enfermedades fungosas $\mathrm{y}$, por lo tanto, la incidencia de las epifitias era mucho menor. Tal ventaja agroclimática de las tierras de riego que se estaban abriendo por obra de la Comisión Nacional de Irrigación fue uno de los factores que contribuyó a que, en los siguientes años, el noroeste se convirtiera en la principal zona triguera del país.

87 BJLLO, Informe de labores de la Secretaría de Agricultura y Fomento (1음 de septiembre de 1942 al 31 agosto de1943), p. 70. 
Si bien es cierto que en la década de 1930 las dificultades presupuestales de la Secretaría de Agricultura impidieron desplegar un aparato institucional y programas de fomento de mucho mayor alcance e impacto, el conjunto de actividades desarrolladas entre los agricultores y el cuerpo de especialistas contribuyó a incrementar los rendimientos del cultivo y, por lo tanto, la disponibilidad del cereal en el mercado interno con 100000 t más a disposición (véase la tabla 8). Por supuesto que tal cantidad no fue suficiente para lograr la autosuficiencia alimentaria y las importaciones continuaron en la siguiente década. Mas no hay que olvidar que, para el cierre del periodo analizado, la agricultura triguera mexicana había alcanzado las mismas cifras que Italia en materia de productividad (véase la tabla 9), uno de los países en donde se realizaron los mayores esfuerzos en materia de mejoramiento para zonas agroclimáticas más hostiles al cultivo.

\section{Tabla 8}

INDICADORES PRODUCTIVOS DEL CULTIVO DEL TRIGO

EN MÉXICO, 1897-1940

\begin{tabular}{llccc}
\hline Periodo & Estimación & $\begin{array}{c}\text { Superficie } \\
(\mathrm{ha})\end{array}$ & $\begin{array}{c}\text { Rendimiento } \\
(\mathrm{kg} / \mathrm{ha})\end{array}$ & $\begin{array}{c}\text { Producción } \\
(\mathrm{t})\end{array}$ \\
\hline \multirow{2}{*}{$1897-1912$} & Promedio & 511344.81 & 569.00 & 290825.63 \\
& Mediana & 495879.00 & 570.00 & 279975.00 \\
$1921-1930$ & Promedio & 481245.80 & 647.80 & 312628.20 \\
& Mediana & 503123.50 & 656.00 & 316248.00 \\
& Promedio & 513174.40 & 774.90 & 399157.00 \\
& Mediana & 496845.00 & 766.00 & 389299.00 \\
\hline
\end{tabular}

FuENTE: elaboración propia basada en Estadisticas históricas.

Mas los fenómenos naturales son de gran complejidad y el efecto de "la reina roja" se hizo sentir en los primeros años de la década de 1940. Las razas de chahuistle evolucionaron atacando buena parte de los trigos mejorados que se desarrollaron en los años previos, lo que afectó profundamente la disponibilidad de 
Tabla 9

COMPARATIVO DE RENDIMIENTOS DE TRIGO

ENTRE PAÍSES, 1870-1939

\begin{tabular}{lcclccc}
\hline & \multicolumn{2}{c}{$1870-1915$} & & \multicolumn{2}{c}{$1916-1939$} \\
\cline { 2 - 3 } \cline { 5 - 6 } País & $q / h a$ & $k g / h a$ & & $q / h a$ & $k g / h a$ \\
\hline Gran Bretaña & 19 & $861.6-965.2$ & & 22 & $997.7-1117.6$ \\
Francia & 13.5 & $612.2-685.8$ & & 15.5 & $702.9-787.4$ \\
Italia & 8.5 & $385.4-431.8$ & & 14 & $634.9-711.2$ \\
España & 7 & $317.4-355.6$ & & 9 & $408.15-457.2$ \\
México & $\mathrm{Sd}$ & 570 & & $\mathrm{Sd}$ & 775 \\
\hline
\end{tabular}

FuENTE: para la estimación de los rendimientos en México, Estadísticas históricas; para los países europeos, Pujol-Andreu, "Wheat varieties".

Nota: para la conversión de quintales a kilogramos se utilizaron las dos equivalencias de quintal prevalecientes en el periodo, el quintal "corto" estadounidense con un valor de $45.35 \mathrm{~kg}$, y el quintal "largo" británico, con una equivalencia de 50.8 kg, razón por la cual se estableció como un rango.

trigo en el mercado nacional. ${ }^{88}$ Había que iniciar de nuevo. Y este nuevo inicio se dio con el convenio de colaboración científica con la Fundación Rockefeller. Mas no todo se perdió. Lo más relevante a destacar es que las nuevas variedades mejoradas, tales como los criollos colorados, y algunos exóticos que lograron aclimatarse, junto con la identificación de ciertos patrones regionales sobre las enfermedades fungosas, fueron las bases de las que se partió y se definió la investigación experimental realizada por el personal de la Fundación Rockefeller. Con ello inició el desarrollo de los futuros híbridos artificiales de laboratorio que originaron la revolución verde en la posguerra. ${ }^{89}$

88 CoTTER, Troubled Harvest; BJLLO, Informe de labores de la Secretaría de Agricultura y Fomento (1o de septiembre de 1942 al 31 agosto de1943).

${ }^{89}$ Los especialistas estadounidenses decidieron iniciar los trabajos de cruzamiento con los mejores trigos criollos desarrollados en aquel momento por su adaptación a los suelos pobres del país y su superioridad ante el ataque del chahuistle. En los primeros experimentos realizados se cruzaron el Lagunero, Colorado de Obregón, Colorado, Querétaro, Aguilera, Pelón Colorado, 


\section{CONCLUSIONES}

Durante las primeras tres décadas del siglo xx se establecieron las bases del fitomejoramiento del cultivo del trigo mediante la colaboración entre agricultores y especialistas de la Secretaría de Agricultura. En síntesis, se experimentó con variedades exóticas y nativas para seleccionar las más resistentes y productivas; el nuevo material genético se reprodujo bajo controles más estrictos; se iniciaron las pruebas de germinación y de desinfección de las semillas, y se estableció la siembra exclusiva de una sola variedad para evitar su deterioro genético en la resiembra; las nuevas semillas se almacenaron y distribuyeron en espacios y medios más adecuados y bajo ciertos parámetros fitosanitarios. La infraestructura en las zonas de sembradío quedó constituida por campos experimentales especializados en trigo, campos de demostración y ensayo, así como los de reproducción de semillas.

En 30 años de esfuerzos en materia de fitomejoramiento (1909-1939) se logró un incremento aproximado de 200 kg más por ha cultivada (1/5 t), y 110000 t más en la producción nacional de trigo que lo registrado en el periodo porfiriano. La superficie cultivada fue la misma, cercana a las 500000 ha, aunque hubo un desplazamiento de la frontera triguera hacia las zonas de riego del norte del país, por sus ventajas agroclimáticas para prevenir enfermedades fungosas, y un cierto detrimento del cultivo en los valles de montaña (muy difícil de estimar).

Más allá de las limitaciones presupuestales y operativas de la Secretaría de Agricultura durante el periodo estudiado y de la

Torreón y Renacimiento con variedades obtenidas en las estaciones experimentales de Texas. En este grupo selecto de trigos mexicanos, también se incluyeron algunas variedades exóticas de gran rendimiento y resistencia a la enfermedad, como el Candeal de la Comarca Lagunera. RFA, fondo 126 6.13, Reporte de las experimentaciones con trigo del Programa de mejoramiento del trigo a cargo de la Oficina de Estudios Especiales de la Secretaría de Agricultura, c. 32: 355, s.f. (1943). 
insuficiencia de la producción nacional para atender la demanda interna, los resultados registrados en México y en otras latitudes en materia de rendimientos del cultivo nos lleva a reflexionar sobre las propias limitaciones de las técnicas de fitomejoramiento en el marco de las principales teorías científicas en boga (la genética de poblaciones y la búsqueda del fenotipo extremo). ¿Era posible que los agricultores alcanzaran mayores rendimientos que los logrados considerando los límites tecnocientíficos de la época? La información obtenida nos muestra que en México se consiguieron rendimientos semejantes a aquellos países europeos de climas y suelos parecidos y en donde se habían hecho esfuerzos para el mejoramiento del trigo.

Todo parece indicar que los trigos modernos mexicanos, los criollos paneros suaves, demostraron su superioridad frente a los híbridos desarrollados en otras latitudes durante las primeras décadas del siglo pasado. Sin negar que hubo resistencias al cambio de prácticas culturales, habría que considerar de entrada las ventajas agronómicas de los trigos criollos frente a los híbridos importados. ¿Cuáles eran las ventajas para los agricultores para su supuesta sustitución? Aparentemente ninguna. No obstante, el mejoramiento del cultivo resultó mucho más complejo de lo que se pensaba dentro del cuerpo de especialistas de la Secretaría. Al final de los años treinta quedaba claro que se requerían estrategias específicas regionales debido a la heterogeneidad agroclimática de las zonas productoras y, por ende, ante el mosaico de enfermedades fungosas. De ahí la diversidad de respuestas del nuevo material genético.

Claro está que estos modestos avances en materia de productividad se dieron con mayor facilidad en aquellas zonas en donde se desarrollaba la agricultura comercial. Las técnicas de fitomejoramiento promovidas por la Secretaría entre los principales productores de trigo permitieron obtener algunas variedades mejoradas potenciando aún más su supuesta superioridad productiva. Los programas de reproducción de semillas y de 
desinfección que promovió el gobierno nacional facilitaron su circulación y comercialización en las principales zonas productoras (y entre los grandes agricultores), especialmente en las tierras del Bajío y del norte, en donde se consolidaban como la principal fuente productiva al cierre de los años treinta. Mas no deja de llamar la atención que los mayores éxitos en la introducción y aclimatación de semillas exóticas de mayor productividad se dieran con las variedades de trigos duros, no solo porque éstas eran originarias de contextos agroecológicos similares a los de México (del Mediterráneo europeo), lográndose aclimatar con relativa facilidad, sino también por intereses de mercado, pues eran estos los de mayor escasez y de creciente demanda por la agroindustria nacional, que así los requería para la elaboración de harinas multipropósito.

Tal como se señaló en la primera parte de este trabajo, las innovaciones biológicas son de periodicidad limitada. Las semillas mejoradas obtenidas durante las primeras décadas del siglo xx se perdieron cuando las razas de chahuistle evolucionaron y se adaptaron a las nuevas variedades acabando con su supuesta mayor resistencia a la enfermedad. Por efecto de la "reina roja" hubo trigos que se perdieron en el tiempo, invisibles por los nombres comunes con los que solía nombrárseles. Quedan algunos trazos de su existencia en ciertas fuentes documentales, pero aún faltan más por identificar. Estas son algunas de las conclusiones preliminares que la investigación realizada hasta el momento nos ha permitido formular, mas queda mucho por hacer para lograr una mayor comprensión sobre los fenómenos agrobiológicos en el México de la primera mitad del siglo xx.

\section{SIGLAS Y REFERENCIAS}

BJLLO Biblioteca Ing. José Luis de la Loma y de Oteyza, Secretaría de Agricultura y Desarrollo Rural, Ciudad de México, México.

RFA Rockefeller Foundation Archives, Nueva York, Estados Unidos. 
Авогтеs, Luis, El agua de la nación. Una historia política de México (18881946), México, Centro de Investigación y Estudios Superiores en Antropología Social, 1999.

Allen, Garland, La ciencia de la vida en el siglo XX, México, Fondo de Cultura Económica, 1983.

Arteaga, Luis, "El proyecto de Valle de Juárez en el estado de Chihuahua”, en Irrigación en México, 1: 5 (sept. 1930), pp. 42-52.

Bancalari, Manuel, "Posibilidad del cultivo de algodón en snr Río Salado", en Irrigación en México,1: 5 (sept. 1930), pp. 68-70.

Bernal, John, La ciencia en la historia, México, Nueva Imagen, Universidad Nacional Autónoma de México, 2007.

Brambila, Alejandro, "La granja experimental en Rodríguez NL”, en Irrigación en México, 1: 1 (mayo 1930), pp. 44-48.

Cara García, Juan Antonio, "Notas para la historia de la fenología: la aportación del INM”, Madrid, Instituto Nacional de Meteorología, 2006.

CAÑón, Javier, Manual del curso sobre genética cuantitativa, Madrid, Universidad Complutense http://webs.ucm.es/info/genetvet/Tema_1.pdf.

Cenvantes, Juan M. y Juan José SaldaÑa, "Las estaciones agrícolas experimentales en México (1908-1921) y su contribución a la ciencia agropecuaria mexicana”, en SALDAÑa (coord.), 2005, pp. 306-348.

Cotter, Joseph Eugene, Troubled Harvest. Agronomy and Revolution in Mexico, 1880-2002, Westport, Connecticut, Londres, Praeger Publishers, 2003.

СоттеR, Joseph Eugene, "Before the green revolution: Agricultural science policy in Mexico, 1920-1950", tesis de doctorado en historia, Santa Bárbara, University of California, 1994.

Crow, James y William Dove, "N. I. Vavilov, Martyr to Genetic Truth. Perspectives. Anecdotal, Historical and Critical Commentaries on Genetics", en Genetics, 134: 1-4(mayo 1993), pp. 338-341.

Dalrymple, Dana G., "Changes in wheat varieties and yields in the United States, 1919-1984”, en Agricultural History, 62: 4 (otoño 1988), pp. 20-36. 
Departamento Agronómico, "La labor de la granja experimental del snR Río Salado N. L.”, en Irrigación en México, 2: 5 (mar. 1931), pp. 419-432.

Derry, Thomas Kingston y Trevor Illtyd Williams, Historia de la tecnología. Desde 1750 hasta 1900, Madrid, Siglo Veintiuno Editores, 1989, t. 3.

Elena Díaz, Alberto y Javier ORdóÑEz, "De la revolución científica a la revolución industrial. La dimensión tecnológica del newtonianismo", en Hispania: Revista Española de Historia, 56: 193 (1996), pp. 541-564.

ERvin, Michael, "The art of possible, agronomists, agrarian reform, and the middle politics of the mexican revolution, 1908-1934", tesis de doctorado en historia, Pensilvania, University of Pittsburg, 2002.

Estadísticas históricas de México, México, Instituto Nacional de Estadística y Geografía, 2015.

Florescano, Enrique, Atlas histórico de México, México, Secretaría de Educación Pública, Siglo Veintiuno Editores, 1983.

Gracida, Juan José y Ana Isabel GrIJALVA, Empresarios, empresas y actividad agrícola en el norte de México, siglo XX. Hermosillo, El Colegio de Sonora, 2017.

Harwood, Johnathan, "Comments on experimentation in Twentieth-Century Agricultural Science", en History and Philosophy of the Life Science, 37: 3 (2015), pp. 326-330.

Hayami, Yujiro y Vernon W. Ruttan, Agricultural Development: An International Perspective, Baltimore, Johns Hopkins University Press, 1985.

Hewitt de Alcántara, Cynthia, La modernización de la agricultura mexicana, 1940-1970, México, Siglo Veintiuno Editores, 1978.

ITIÉ, Gabriel, “50 años de agricultura en México”, en Revista de la Sociedad Mexicana de Historia Natural, xxi: 1 (jun. 1960), pp. 63-77.

Kohl, Man Mohan y Daniel Martino (eds.), Explorando altos rendimientos del trigo, Uruguay, INIA-CIMMYT,1997.

México en el siglo XX, panorama estadístico, México, Instituto Nacional de Estadística y Geografía, 2000. 
Olea Franco, Adolfo, "One century of Higher Education and Research in Mexico (1850s-1960s), with a preliminary survey on the same subjects in the United States", tesis de doctorado en historia, Massachusetts, Harvard University, 2001.

Olmstead, Alan y Paul Rhode, Creating Abundance: Biological Innovation and American Agricultural Development, Cambridge, Cambridge University Press, 2008.

Olmstead, Alan y Paul Rhode, "Biological innovation and productivity growth in the antebellum cotton economy", Working paper 14142, en National Bureau of Economic Research (jun. 2008), pp. 1123-1171. http://www. nber.org/papers/w14142, 2008b. Consultado el 22 de enero de 2019.

PeÑa, Bernabé, "Cultivo de trigo en el Sistema Nacional de Riego Núm. 1 Presidente Calles”, en Irrigación en México, 10: 1 (ago. 1935), pp. 61-76.

PeÑA, R., Iván Ortiz-Monasterio y K. SAyre, "Estrategias para mejorar (o mantener) la calidad panadera en trigo de alto potencial en rendimiento", en Kohli y Martino (eds.), 1997, pp. 287-304.

Pujol-Andreu, Josep, "Wheat varieties and technological change in Europe, 19th and 20th centuries: New issues in economic history", en Historia Agraria, 54 (ago. 2011), pp. 71-103.

Reynolds, M. P., A. J. D. Pask, D. M. Mullan y P. N. Chávez-Dulanto (eds.), Trigo. Fitomejoramiento fisiológico I. Enfoques interdisciplinarios para mejorar la adaptación del cultivo, México, сіммYт, 2013.

Rivas, Eva, "La constitución de las bases productivas de la fruticultura moderna en el noreste, 1895-1950”, en Gracida y GrIJALVA (coords.), 2017, pp. 145-183.

Rivas, Eva, "Cambio tecnológico, dinámica regional y reconversión productiva en el norte de México. La Comarca Lagunera, 1925-1975”, tesis de doctorado en historia, Madrid, Universidad Complutense, 2011.

Rodríguez, José, Producción y consumo del trigo en México, México, Secretaría de Agricultura y Recursos Hidráulicos, 1981.

Russell, Edmund, "Evolutionary History: Prospectus for a New Field”, en Global History Review, 4 (dic. 2011), pp. 204-228. 
Russell, Edmund, James Allison, Thomas Finger, John Brown, Brian BALOGH y Bernard CARLSON, "The Nature of Power: Synthesizing the History of Technology and Environmental History", en Technology and Culture, 52 (abr. 2011), pp. 246-529.

Saldaña, Juan José (coord.), La casa de Salomón en México. Estudios sobre la institucionalización de la docencia y la investigación científicas, México, Universidad Nacional Autónoma de México, 2005.

SENASICA, La presencia de la sanidad vegetal en la agricultura mexicana del siglo XX, México, Secretaría de Agricultura, Ganadería y Pesca, 2016.

Serrano, Javier y Eva Rivas, “Teoría y práctica en la producción de trigo estadounidense”, en Historia, 396: 1 (2018).

"Resultados obtenidos de algunas semillas nuevas de trigo", en El Campesino. Boletin de la Sociedad Nacional de Agricultura, 33: 9 (feb. 1902), pp. 231-233.

Sunyer Martín, Pere, “Temporal y regadío en el agro mexicano. Política y agricultura en el México de principios del siglo xx”, en Scripta Nova: Revista Electrónica de Geografía y Ciencias Sociales, 10 (2006), pp. 741-798.

TRue, Charles, A History of Agricultural Experimentation and Research the United States, 1607-1925, Washington, United States Department of Agriculture, Miscellaneus Publications, núm. 251, 1937.

Vilmorin, Henry, Los trigos para cultivo. Conferencia dada en la Asociación de la Molinería Francesa, traducción de José Gascón, Madrid, 1894.

Zuleta, María Cecilia, "La Secretaría de Fomento y el fomento agrícola en México, 1876-1910: la invención de una agricultura próspera que no fue", en Mundo Agrario. Revista de Estudios Rurales, 1: 1 (segundo semestre 2000), http://www.memoria.fahce.unlp.edu.ar/art_revistas/pr.626/pr.626.pdf 